\title{
A VISCOPLASTIC CONSTITUTIVE MODEL WITH STRAIN RATE VARIABLES FOR ASPHALT MIXTURES' NUMERICAL SIMULATION
}

\author{
José Manuel González*, Juan Miquel Canet*, Sergio Oller*, and Rodrigo Miró ${ }^{\dagger}$ \\ Department. of Materials and Structures Análisis in Civil Engineering. \\ Universidad Politécnica de Cataluña \\ International Center for Numerical Methods in Engineering (CIMNE). \\ Jordi Girona 1-3, Building C1 Campus Norte UPC, 08034 Barcelona, Spain. \\ E-mail: Jglez@cimne.upc.edu - Fax. (+34)93.401.10.48 \\ E-mail: canet@cimne.upc.edu \\ E-mail: sergio.oller@upc.es \\ Department of Transportation Infrastructures. \\ Universidad Politécnica de Cataluña \\ Jordi Girona 1-3, Módulo C1 Campus Norte UPC, 08034 Barcelona, Spain. \\ E-mail: r.miro@upc.edu
}

\begin{abstract}
The study and development of recycling techniques for pavements is an increasing activity in engineering nowadays. This research line demands a more realistic characterization of the material properties with the aim of simulate the asphalt mixture's response placed into a multilayered system over granular bases, under dynamic loads, considering also temperature variation or strenght reduction for cyclic loads.

In order to improve the current formulations, a new viscoplastic model has been developed assuming the strain rate dependency of the material's response observed in the experimental tests. The strain rate variable affects in a significant way the Young modulus and the viscosity parameter of the model. According to these hypothesis constitutive equations have been formulated. The mechanical variables involved have been calibrated according to experimental results, developing new expressions for the strain rate dependent parameters. The new viscoplastic model permit us to characterize the material's response with a few mechanical values, easily obtained from standard laboratory tests. The results obtained show a good approximation to experimental laboratory curves for different rates of loading and temperatures.

The model has been applied to simulate the response of a real flexible pavement structure conformed by two asphalt layers over two granular bases, that's materials with different constitutive behaviors. Experimental tests in the recycled track have been
\end{abstract}


made obtaining the horizontal strain evolution under dynamic load. Different loading rates and temperatures, as well as cracked and continuum pavement responses have been considered in the study. Strains were measured in the interface between the two asphalt layers and simulated using the here proposed model offering a fairly good approximation of the real response observed in the track, although the degree of variation even in the experimental curves is quite high.

The results of this study represent a proper base for further developments in structural analysis of pavement layers, considering more complex phenomena, determinant in the long term material's response, to develop a numerical tool for pavements' design and lifetime prediction.

KEYWORDS: Asphalt, pavement, viscoplastic model, Young modulus, viscosity, strain rate, stresses.

PACS CODES: Fatigue materials treatment: 81.40.N. Constitutive relations: 83.20.

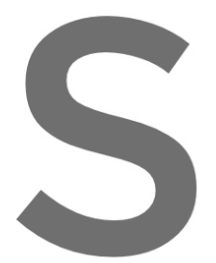

Plasticity materials treatment: 81.40.L. Plasticity rheology: 83.50. Finite element

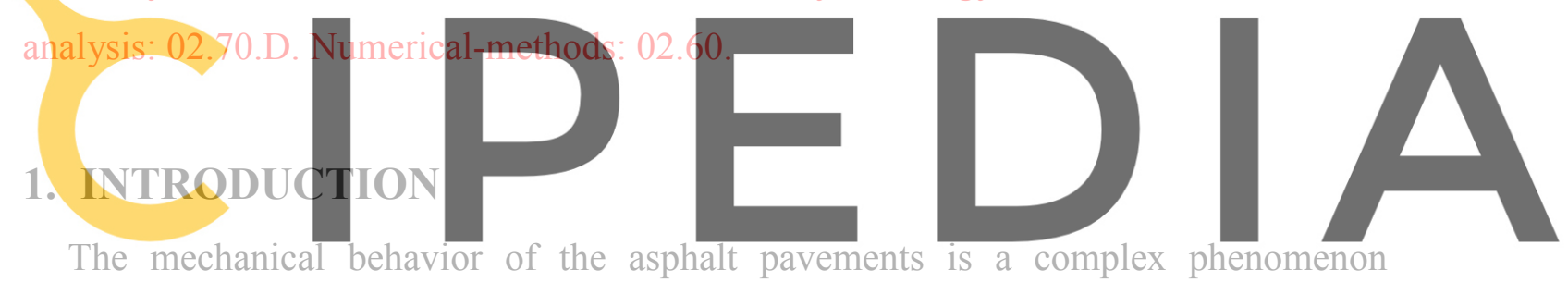

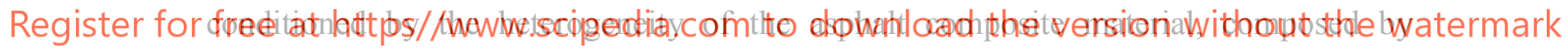

bitumen and aggregates. This complexity increases when the asphalt mixture interacts

with a multilayered system conformed by a bituminous layer and granular layers, that's materials with very different mechanical behavior. The proposed model for this behavior simulation can be applied to improve the design methods for flexible pavement tracks and the short and long term response analysis of the structure as a powerful tool to support the new recycling techniques.

The asphalt mixture as a primary material shows a time dependent behavior. The numerical modelization of its behavior has led to viscous formulations, based in the elastic-viscoelastic correspondence principle [4] after some elastic approximations or empirical results.

On the other hand, experimental tests in the laboratory show a clear strain rate dependency in its response. In order to improve the modelization of the mechanical behavior a new appropriate formulation has been developed based in the viscoplastic 
model [1] including the influence fo the strain rate variable $(\dot{\varepsilon})$ in the constitutive parameters.

The new model has been implemented in a Finite Element code, validated with preexistent results for viscoplastic model [3] and calibrated according to experimental results, for different loading rates and temperatures showing fairly good approximations in a wide range of values.

After the calibration, the new model has been applied to reproduce the behavior of a real pavement conformed. Experimental strain-time evolution curves in the track have been obtained and used to verify the simulation results, for different loading speeds and temperatures.

\section{PAVEMENT'S MECHANICAL BEHAVIOR ANALYSIS}

The approach to the simulation of pavement's mechanical behavior analysis has usually led to elastic solutions which simplify the problem and offers reasonably good results for asphalt mixture conforming for a multilayered system. However, the specific
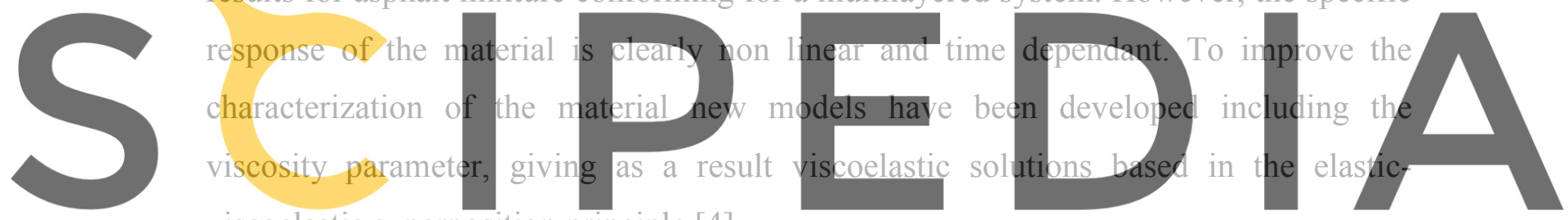

viscoelastic superposition principle [4]

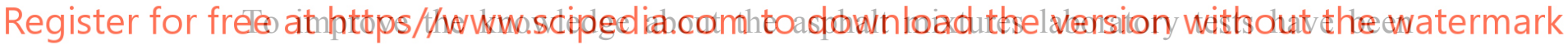

made. The strength - displacement curves obtained show a highly non linear response.

Additionally, different curves have been obtained for different rates of loading to remark the dependency of this variable in the material's response, which will be included in the model.

The described behavior drive to a strain rate dependent formulation, where some of its mechanical parameters depends on the strain rate tensor's values. Once defined the constitutive variables, the range of values and the influence in the response of every one has been studied, to calibrate de model.

According to the experimental result's simulation some material properties can be mentioned:

- The elastic range is not significant. The non linear behavior comes up for low stresses, and the yield stress value is not important in the response, but its constitutive behavior beyond this threshold limit. It can be approximated to $40 \leq \sigma_{\text {yield }} \leq 60 \mathrm{kN} / \mathrm{m}^{2}$. 
- The elastic young modulus is strain rate dependant $E(\dot{\varepsilon})$. This property is much clearer in the non linear range, which is almost the whole domain of the response.

The Young modulus is obtained in the calibration process for three strain rate values $\{E(\dot{\varepsilon}), E(10 \cdot \dot{\varepsilon}), E(100 \cdot \dot{\varepsilon})\}$. The expression proposed for the Young Modulus in relation with the strain rate is

$$
\left.E(\dot{\varepsilon}, T)=E_{0} \cdot K_{E}(T)^{\log \left(\frac{\dot{\varepsilon}}{\dot{\varepsilon}_{0}}\right.}\right) \leq E_{\text {elastic }}
$$

where $\mathrm{E}_{0}$, is the Young modulus for a reference strain rate $\dot{\varepsilon}_{0}$, and $K_{E}$ is a constant of the material which depends on the temperature. This constant needs to be calibrated with the experimental tests.

The viscosity is also strain rate dependant, altought this dependency is lower than the one observed in the Young modulus. After the calibration process, the expression proposed for the viscosity related with the strain rate is
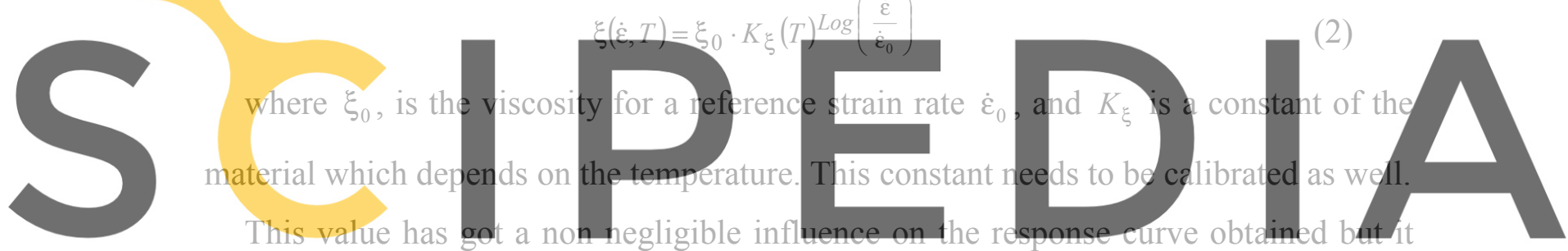

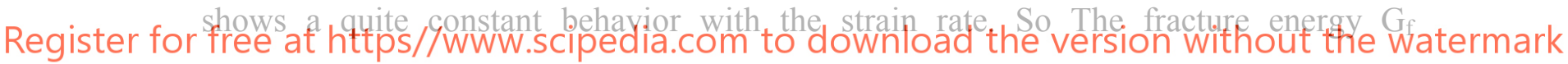
associated to the material is considered constant. The model considers a different value for the fracture energy in tension $\mathrm{G}_{\mathrm{f}}$ and crushing energy in compression $\mathrm{G}_{\mathrm{C}}[2]$.

\section{VISCOPLASTIC MODEL WITH STRAIN RATE}

\section{DEPENDENT YOUNG MODULUS AND VISCOSITY.} MATHEMATICAL FORMULATION

\section{1.- Introduction}

The purposed model is generalization of the classical viscoplastic formulation, taking into account the influence of the strain rate in the constitutive parameters. This influence have been studied to reach strain rate dependent expressions for the Young modulus and the viscosity, taking as reference the experimental response observed in the laboratory. 
This strain rate can be represented as a complex rheological model composed by a string in series with $\mathrm{N}$ chains combining a friction element and a dashpot for each chain, placed all of them in parallel ( Figure 1).

\section{Place for Figure 1}

Every chain conformed by a friction element and a dashpot has got a different time of delay associated, so for a fixed stress applied with a determined strain rate the response of every single chain is different, due to the collocation of the chains placed in series. So, depending on the $\mathrm{N}$ times of delay, the whole response of the model is provided for a different number of chains, that's, all the dashpots or not all but some of them.

This combination of $\mathrm{n}$ frictional-viscous elements permits to consider a different response for every strain rate, characterized for an equivalent time of delay of the whole set described as $\tau_{\text {equivalent }} \equiv \tau(\dot{\varepsilon})$. This model can be simplified by means of a single
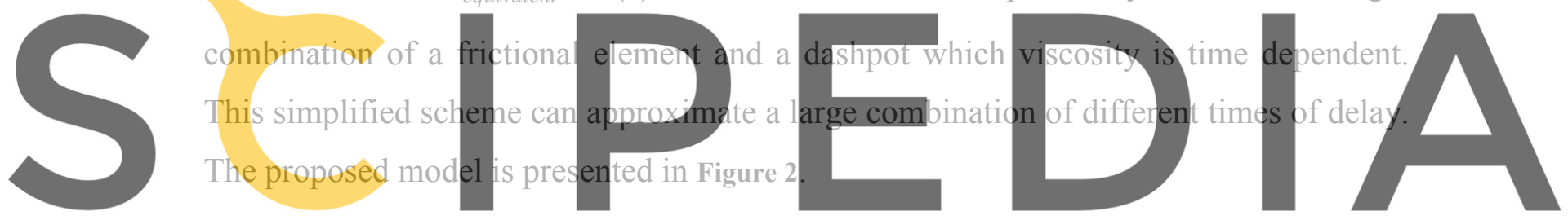

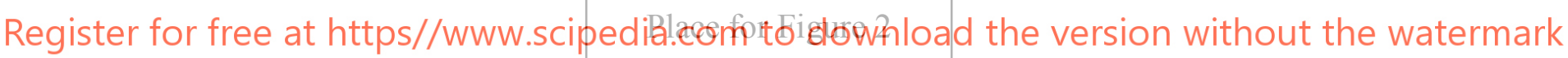

As a summary, the presented model is able to provide a strain rate dependent response for a fixed stress applied, calibrating two strain rate functions for the Young modulus and the viscosity.

The proposed viscoplastic model is presented assuming small strains and constant temperature during all the mechanical process. This model can be extended for small elastic strains and large viscoplastic strains.

\section{2.- Thermodynamical framework for the purposed model}

The new viscoplastic model is formulated in the frame of the classical thermodynamic theory based in the first and second principles, which are assumed in the Clausius - Duhem expression for adiabatic and isothermal mechanical problem [2]: 


$$
\Xi_{m}=-\dot{\psi}+\frac{\sigma: \dot{\varepsilon}}{\rho} \geq 0
$$

where $\mathrm{E}_{\mathrm{m}}$ is the dissipation energy expressed as a function of the free energy rate $(\dot{\psi})$ and the mechanical energy density $(\sigma: \dot{\varepsilon})$. The purposed model considers the temperature as a constant during all the process.

Applying the Coleman's method [2] the hyperelastic form is obtained to express the constitutive (4) and the energy dissipation (5).

$$
\sigma=\rho \frac{\partial \psi}{\partial \varepsilon} \quad \text { (4) } \quad \Xi_{m}=-\rho \frac{\partial \psi}{\partial \mathbf{q}}: \dot{q} \geq 0
$$

\section{So to formulate the model a free energy function is to be defined, to know the} relation between de stresses and strains and the energy dissipation. The function for the
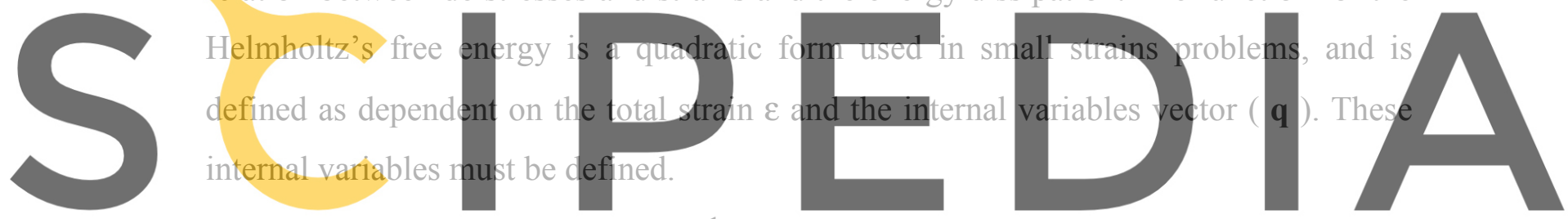

$$
\psi(\varepsilon, q)=\frac{1}{3} \varepsilon^{e}: \mathbf{C}(\dot{\varepsilon}): \varepsilon^{e}+\psi^{\nu p}
$$

(6)

Register for free at https//www.scipedia.copm to download the version without the watermark

where $\mathrm{C}(\dot{\varepsilon})$ is the constitutive tensor, $\dot{\varepsilon}$ is a function of the components of strain rate tensor, and $\psi^{v p}$ is a viscoplastic component of the free energy [13] which expression is detailed as follows:

$$
\psi^{v p}=\frac{1}{\rho} \kappa^{p}
$$

where $\kappa^{\mathrm{p}}$ is the fraction of viscoplastic energy dissipated normalized to the constitutive value of the fracture energy in tension and compression $\left\{g_{f}, g_{c}\right)[2]$.

\section{3.- Description of the numerical model proposed}

The proposed model has been developed to reproduce the stress-strain behavior of an asphaltic pavement for a constant temperature. So that, a set of mechanical variables has been chosen to build the model:

- Free variables $\{\boldsymbol{\varepsilon}\}$ 
- Internal variables $\left\{\boldsymbol{\varepsilon}^{v p}, \kappa^{v p}, C^{v p}\right\}$

where $\varepsilon^{\mathrm{vp}}$ is the viscoplastic strain, which evolution law is presented below, $\kappa^{\mathrm{vp}}$ the fraction of viscoplastic energy dissipated which evolution law is defined as

$$
\dot{\boldsymbol{\kappa}}^{p}=\left[\frac{r(\boldsymbol{\sigma})}{g_{f}}+\frac{1-r(\boldsymbol{\sigma})}{g_{c}}\right] \cdot \boldsymbol{\sigma}: \dot{\boldsymbol{\varepsilon}}^{v p}
$$

where $r(\sigma)$ is an escalar function of the stress tensor $\sigma$ to relate the dissipated energy for tension or compression with the tensional state [2].

$\mathrm{C}^{\mathrm{vp}}$ is the uniaxial equivalent strength of the material expressed as a function of the value of $\mathrm{K}^{\mathrm{vp}}$ and is treated as an internal variable, which evolution's law is expressed as

\section{follows}

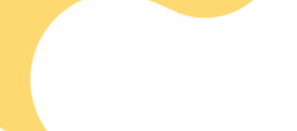

\section{$\dot{C}=h_{c} \cdot \dot{\kappa}=C \cdot\left[\frac{r(\boldsymbol{\sigma})}{C_{T}} \frac{d C_{T}}{d \kappa^{p}}+\frac{1-r(\boldsymbol{\sigma})}{C_{C}} \frac{d C_{C}}{d \kappa^{p}}\right] \cdot \dot{\kappa}$}
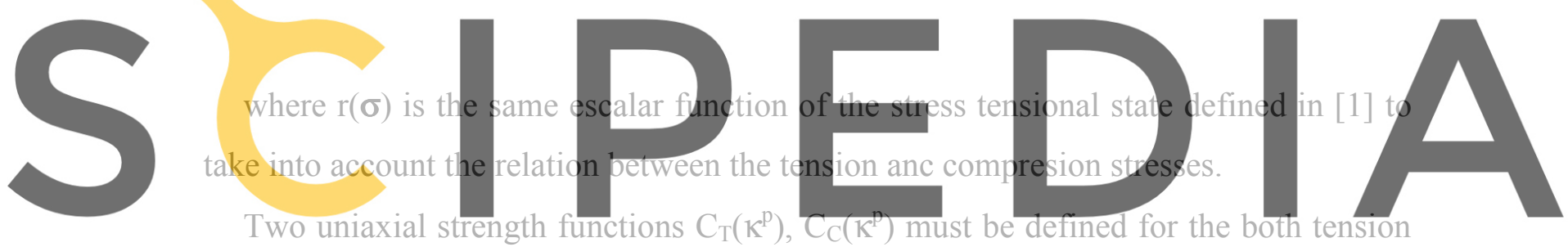

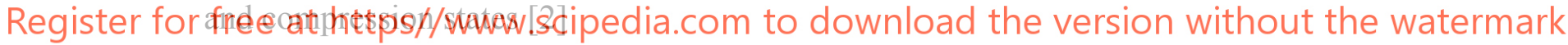

Some hypothesis are assumed to define the present constitutive model and energy's dissipation expression.

The total strain is defined as addition of elastic and plastic strain components:

$$
\boldsymbol{\varepsilon}=\boldsymbol{\varepsilon}^{\text {elastic }}+\boldsymbol{\varepsilon}^{\text {viscoplastic }} \Rightarrow \boldsymbol{\varepsilon}=\boldsymbol{\varepsilon}^{\mathrm{e}}+\boldsymbol{\varepsilon}^{\mathrm{vp}}
$$

A yield function is defined to establish a limit between the elastic and viscoplastic behaviour, depending on the stress state and the internal variables at every calculation point. The stress state for the yield function is assimilated to the uniaxial equivalent stress $\left\{\mathrm{C}^{\mathrm{vp}}\right\}$ and it is treated as an internal variable. This function is analogous to the yield function in plasticity, but in this case, stress states that exceed this limit are allowed. Taking this yield surface as reference, an overstress function [2] can be defined as

$$
F(\boldsymbol{\sigma}, \mathbf{q})=\frac{f(\boldsymbol{\sigma})}{C^{v p}}-1
$$


where $f(\boldsymbol{\sigma})$ is an escalar function depending on tensorial arguments for the uniaxial equivalent stress according to a yield criteria.

To obtain the evolution law for the viscoplastic strain an overstress function needs to be defined. In general this overstress function can be expressed as follows

$$
\langle\phi[F(\boldsymbol{\sigma} ; \mathbf{q})]\rangle=\mid \begin{array}{cccc}
0 & \forall F \leq 0 & \Rightarrow & \text { Elastic behavior } \\
\phi[F(\boldsymbol{\sigma} ; \mathbf{q})] & \forall F \geq 0 & \Rightarrow & \text { Viscoplastic behavior }
\end{array}
$$

Duvaut - Lions form is assumed for $\phi$ function, so $\phi[F(\boldsymbol{\sigma} ; \mathbf{q})]=F(\boldsymbol{\sigma} ; \mathbf{q})$ as indicated in $[2]$

The formulation of the viscoplasticity does not impose the consistency condition. It is in the plasticity theory in long term, when both theories coincides. So this equality
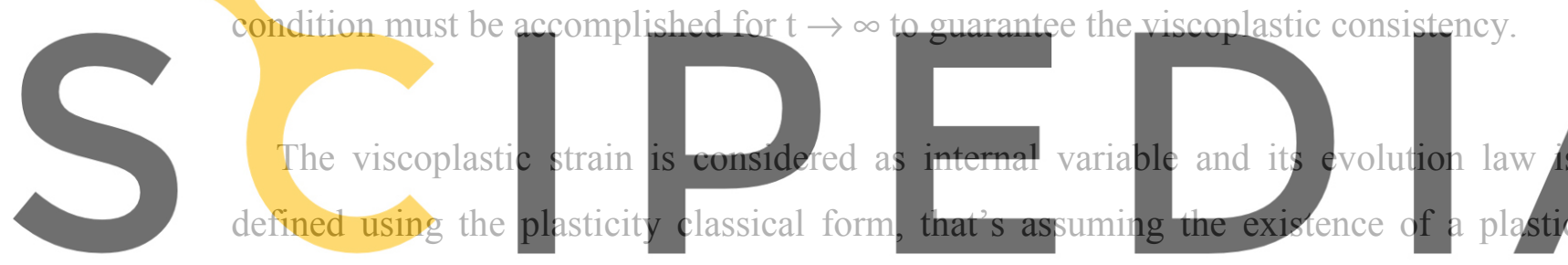

potential function $G(\sigma, q)$. For particular cases ( associative plasticity ) this function

Register for free at https//www.scipedia.com to download the version without the watermark becomes equal to the yield surface $F(\sigma, q)$.

The plastic strain rate is defined as a function of this potential and a viscoplastic parameter $\lambda^{\mathrm{vp}}$, as expressed in the following equation.

$$
\dot{\boldsymbol{\varepsilon}}^{v p}=\lambda^{v p} \cdot \frac{\delta \mathbf{G}}{\delta \boldsymbol{\sigma}}=\lambda^{v p} \cdot \mathbf{g} \Rightarrow d \boldsymbol{\varepsilon}^{v p}=\lambda^{v p} \cdot \mathbf{g} \cdot d t
$$

The viscoplastic parameter $\lambda^{\mathrm{vp}}$ is computed in order to reach the consistency condition, as indicated in equation

$$
\lambda^{v p}=\frac{\langle\phi[F(\boldsymbol{\sigma} ; \mathbf{q})]\rangle}{\xi(\dot{\varepsilon})}=\frac{\langle F(\boldsymbol{\sigma} ; \mathbf{q})\rangle}{\xi(\dot{\varepsilon})}
$$


According to this definition, the viscoplastic parameter remains always positive for viscoplastic behavior, or zero for elastic behavior. In this way the viscoplastic consistency is guaranteed at every moment by the following condition

$$
\langle F(\boldsymbol{\sigma} ; \mathbf{q})\rangle-\lambda^{v p} \cdot \xi(\dot{\varepsilon})=0
$$

The above formulation allows to define the viscoplasticity as a time dependant regularization of the plasticity theory, which allows a relaxed transition between the elastic and inelastic behavior. The plastic and elastic are the extreme behaviors observed with this formulation as explain in Table 1.

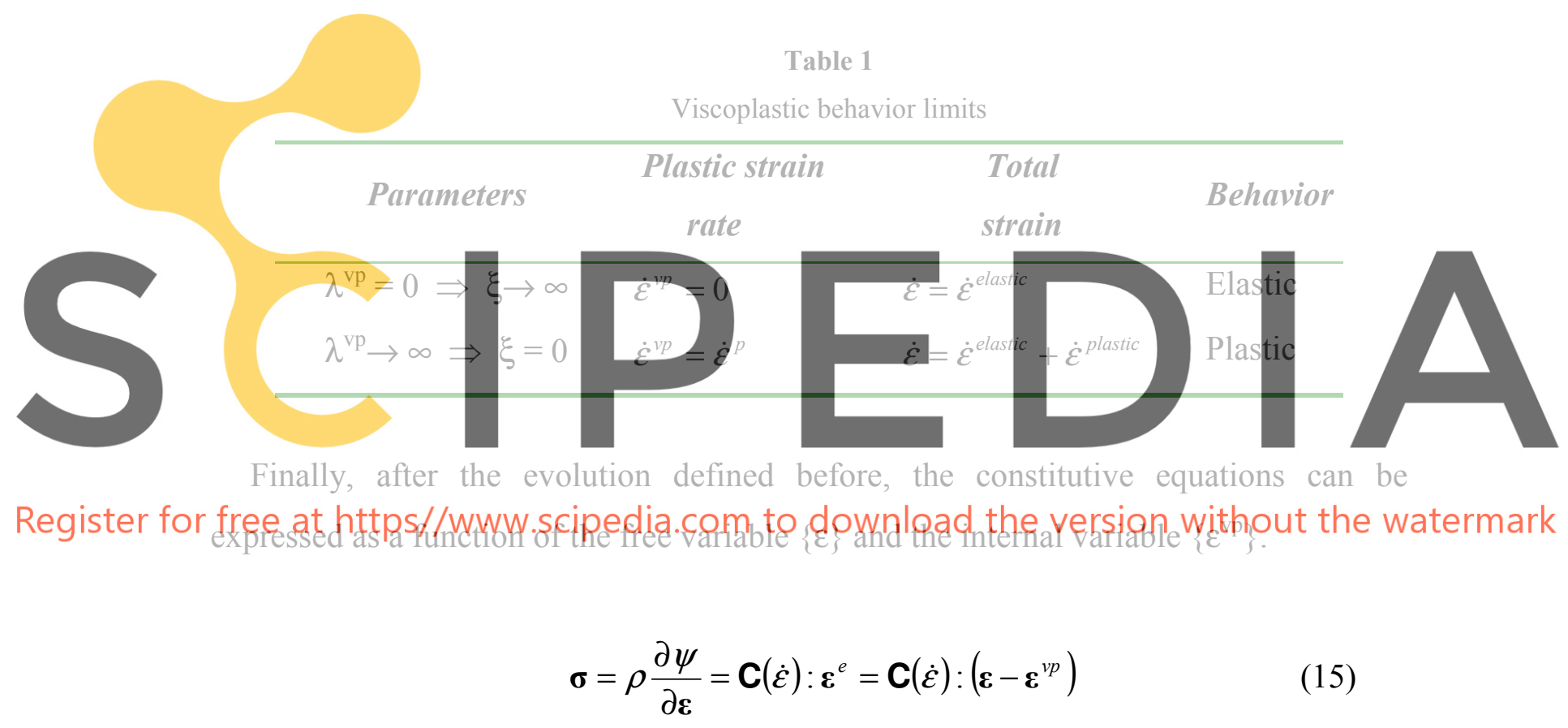

On the other hand, the energy dissipation can be expressed as follows

$$
\Xi_{m}=-\rho \frac{\partial \psi}{\partial \boldsymbol{\varepsilon}^{v p}}: \dot{\boldsymbol{\varepsilon}}^{v p}=\left[\mathbf{C}(\dot{\boldsymbol{\varepsilon}}): \boldsymbol{\varepsilon}^{e}\right]: \dot{\boldsymbol{\varepsilon}}^{v p}=\left[\mathbf{C}(\dot{\varepsilon}): \boldsymbol{\varepsilon}^{e}\right]:\left[\lambda^{v p} \cdot \frac{\delta \mathbf{G}}{\delta \boldsymbol{\sigma}}\right]
$$

The stress rate can be calculated from the derivatives respect to the free and internal variables 


$$
\begin{gathered}
\dot{\boldsymbol{\sigma}}\left(\boldsymbol{\varepsilon}^{e}, \dot{\boldsymbol{\varepsilon}}\right)=\frac{\partial \boldsymbol{\sigma}}{\partial \boldsymbol{\varepsilon}^{e}}: \dot{\boldsymbol{\varepsilon}}^{e}+\frac{\partial \boldsymbol{\sigma}}{\partial \dot{\boldsymbol{\varepsilon}}}: \frac{\partial(\dot{\boldsymbol{\varepsilon}})}{\partial t} \\
\dot{\boldsymbol{\sigma}}\left(\boldsymbol{\varepsilon}^{e}, \dot{\boldsymbol{\varepsilon}}\right)=\left[\mathbf{C}(\dot{\varepsilon}):\left(\dot{\boldsymbol{\varepsilon}}-\dot{\boldsymbol{\varepsilon}}^{v p}\right)\right]+\frac{\log \left(K_{E}\right)}{\dot{\varepsilon}}\left[\left(\mathbf{C}(\dot{\varepsilon}) \otimes \frac{\partial \dot{\varepsilon}}{\partial \dot{\boldsymbol{\varepsilon}}}\right):\left(\boldsymbol{\varepsilon}-\boldsymbol{\varepsilon}^{v p}\right)\right]: \ddot{\boldsymbol{\varepsilon}}
\end{gathered}
$$

The constitutive tensor $\mathbf{C}$ has been defined depending on the strain rate escalar value $\overline{\dot{\varepsilon}}$. This escalar value has been obtained from de following definition

$$
d \dot{\omega}=\sigma: d \dot{\varepsilon}=\bar{\sigma}: d \overline{\dot{\varepsilon}} \Rightarrow d \overline{\dot{\varepsilon}}=\frac{\boldsymbol{\sigma}: d \dot{\boldsymbol{\varepsilon}}}{\bar{\sigma}} \Rightarrow \overline{\dot{\varepsilon}}=\int_{t} d \overline{\dot{\varepsilon}}
$$

\section{in which $\bar{\sigma}=f(\sigma)$}

In this way a escalar equivalent strain rate is defined at each point on each time, which determines the strain rate dependent mechanical parameters.
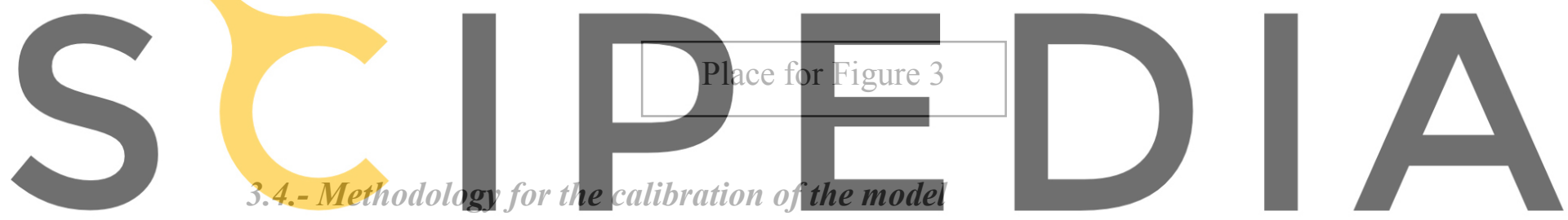

After the model and its constitutive variables description, a methodology to Register for free at https//www.scipedia.com to download the version without the watermark determine the necessary parameters to calibrate the model is presented.

The starting point is the characterization of the asphalt mixture, its composition and properties. The values will be obtained for a type of mixture and for a fixed temperature considered as constant.

In this case, at least two direct tensile tests are needed, for two different loading rates ( $\dot{\varepsilon}$ and $10 \dot{\varepsilon}$ ). The features of the referenced test and the loading function are described in section 5 .

The experimental curves can be reproduced employing the model for both strain rates considered. The constitutive values of the model are summarized below.

The Young modulus value highly affects the slope of the curve in the loading interval, and it's strain rate dependent. Assuming the hypothesis of the model it grows geometrically with a factor $\mathrm{K}_{\mathrm{E}}(1)$ when the strain rate grows with a factor 10 . This constant must determined from the values provided by the simulation process. 
The value for the Poisson's ratio value is assumed as a constant of the material and its influence in the results is not significant. A value $v=0,3$ for the Poisson's ratio is assumed

The stresses observed in the linear interval of the response are not significant in the whole material's response in comparison with the maximum strength provided for the asphalt mixture. The yield stress has been approximated to $40 \mathrm{kN} / \mathrm{m}^{2}$, altought any value around $50 \mathrm{kN} / \mathrm{m}^{2}$ could be considered.

The viscosity parameter is very sensitive in the simulation of the reference test. The model has considered a strain rate dependency following a function (2) depending on a $\mathrm{K}_{\xi}$ constant which must be determined from the two values of the viscosities found in the simulation process.

The fracture energy is assumed as a constant value independent of the strain rate, to be determined for every temperature. The model considers a different value for the fracture energy $G_{f}$ and the crushing energy $G_{c}$. The fracture energy value for the experiments is $\mathrm{G}_{\mathrm{f}}=0,020 \mathrm{kN} / \mathrm{m}$

\section{EQUILIBRIUM IN THE FINITE ELEMENT FORMULATION}

The model has been implemented in a computational code based in the finite element method which solves the dynamic equilibrium equation for a solid subjected to external actions. Non linear behavior comes from the stresses obtained from the constitutive model formulated (see section 3). The dynamic equilibrium equation for a single domain $\Omega^{e}$ (single finite element) belonging to the discrete continuum $\Omega$ can be written as,

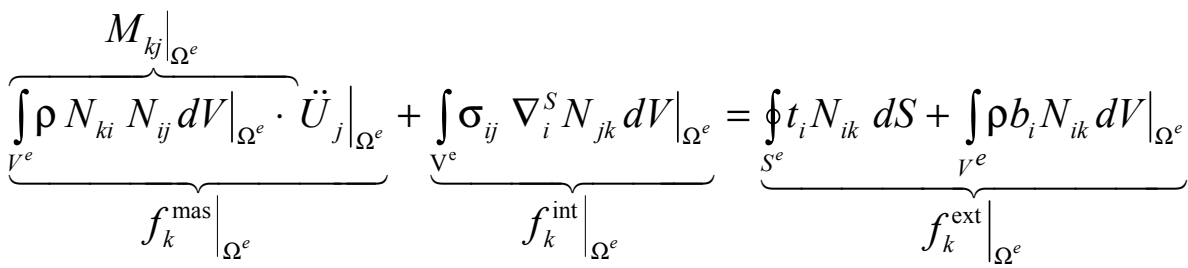

$$
\begin{aligned}
& M_{k j} \ddot{U}_{j}+f_{k}^{\mathrm{int}}=f_{k}^{\mathrm{ext}} \in \Omega^{e}
\end{aligned}
$$

Where $N_{i j}=\mathbf{N}(x, y, z)$ is the shape function for the $\Omega^{e}$ finite element, $\left.f_{k}^{\text {int }}\right|_{\Omega^{e}},\left.f_{k}^{\text {mas }}\right|_{\Omega^{e}}$ and $\left.f_{k}^{\text {ext }}\right|_{\Omega^{e}}$ are the internal, inertial and external forces on the elemental continuum $\Omega^{e},\left.\quad \ddot{U}_{j}\right|_{\Omega^{e}}$ is the acceleration, $\left.M_{k j}\right|_{\Omega^{e}}$ is the mass matrix and 
$\left.\overline{\mathrm{B}}_{i j k}\right|_{\Omega^{e}}=\left.\nabla_{i}^{S} N_{j k}\right|_{\Omega^{e}}$ is the compatibility strain tensor. The non linear behavior appears when the equilibrium is not reached between the internal, external and inertia forces at any $\Omega^{e}$ element (see equation (19) ). The global equilibrium over all the discrete continuum $\Omega$ is obtained assembling the elemental equilibrium forces throughout the A operator [5].

$$
0=\underset{\Omega^{e}}{\mathrm{~A}}\left[f_{k}^{\mathrm{mas}}+f_{k}^{\mathrm{int}}-f_{k}^{\mathrm{ext}}\right]_{\Omega^{e}}=\left.\Delta f_{k}\right|_{\Omega}
$$

To reach the global equilibrium state, the residual forces $\left.\Delta f_{k}\right|_{\Omega}$ are linearized using the Taylor series, approaching the velocity and the acceleration by the Newmark's algorithm and then substituting into de dynamic equilibrium equation (20).

An iterative process formulated by Newton Raphson's drive to solve the equation (21) allowing vanish the residual forces, obtaining in this way the balance of the solid. At this stage, the stress-strain relationship at any internal point used to equilibrates the internal and the external forces give the solution for the non linear problem.

$$
0={ }^{i+1}[\Delta \mathbf{f}]_{\Omega}^{t} \cong^{i}[\Delta \mathbf{f}]_{\Omega}^{t}+\underbrace{\left[\mathrm{M} \frac{\partial \ddot{\mathbf{U}}}{\partial \mathbf{U}}+\mathrm{K}^{T}+\mathrm{D}^{T} \frac{\partial \dot{\mathbf{U}}}{\partial \mathbf{U}}-\frac{\partial \mathbf{f}^{\text {ext }}}{\partial \mathbf{U}}\right]_{\Omega}^{t}}_{i \mathbf{J} t_{\Omega}^{t}} \cdot{ }^{i+1}[\Delta \mathbf{U}]_{\Omega}^{t}
$$

where the matrix involved are all of them defined in the domain $\Omega$ as follows [2] $\left[\mathrm{K}^{T}\right]_{\Omega}=\underset{\Omega^{e}}{\mathrm{~A}} \int_{\mathrm{V}^{\mathrm{e}}}\left(\boldsymbol{\nabla}^{S} \mathbf{N}\right): \mathbf{C}:\left(\boldsymbol{\nabla}^{S} \mathbf{N}\right) d V$ stiffness matrix for the the constitutive tensor $\mathbf{C}$ $[\mathrm{M}]_{\Omega}=\underset{\Omega^{e}}{\mathrm{~A}} \int_{\mathrm{V}^{\mathrm{e}}} \rho \mathbf{N}: \mathbf{N} d V$ mass matrix $\left[\mathrm{D}^{T}\right]_{\Omega}=\underset{\Omega^{e}}{\mathrm{~A}} \int_{\mathrm{V}^{\mathrm{e}}}\left(\nabla^{S} \mathbf{N}\right): \xi^{T}:\left(\nabla^{S} \mathbf{N}\right) d V$ damping matrix for the viscosity $\xi$

The constitutive non-linearity takes into account the variation of the mechanical properties of the material during the process, which affects to the constitutive tensor $C_{i j k l}(\dot{\varepsilon})$, and so, to the relation between stresses and strains.

\section{APPLICATION OF THE MODEL TO THE SIMULATION OF} ASPHALT MIXTURES' BEHAVIOR

To calibrate and verify the purposed model an accurate knowledge of the material's stress-strain response is necessary, as well as the mechanical processes involved in the degradation and failure of the pavement. Asphalt conforms a porous mixture using 
different materials like aggregates, filler and the bituminous mix. The interaction of all these components determines a complex behavior.

One of the most important causes of failure is the cracking of the asphalt mixing material. In the asphalt layer, small porus and microcracks exists, especially in the interphases between the components. When the pavement is submitted to traffic loads or temperature's variations, internal stresses and permanent strains are generated. This tensional states causes new cracks and the propagation of the microcracks already existing driving the material to the loss of stress and stiffness.

This cracking propagation is mostly influenced by the tensile stresses, so in this study it's considered that the most important variable in the pavement's failure by cracking is the horizontal strain, under tension stress states.

For this reason, the Direct Tensile Test has been chosen as an appropiate test to reproduce the behaviour of the material under tensile stresses. This test will be employed to study the stress - strain response of the material, the constitutive variables involved and its influence on the results, and the expressions for the constitutive parameters to calibrate the model.

\section{1. - Experimental test for the material characterization. Direct Tensile Test}

The direct tensile test ( DTT ) enables the application of uniaxial tensional states to the specimen placed between two metallic gripping devices. Some epoxy resin are used to join the specimen to the devices, so as to guarantee that the material is submitted to normal forces along the vertical axe, and the stress applied is really uniaxial as expected. ( Figure 4 )

\section{Place for Figure 4}

The test can be performed under static loading, applying a prescribed displacement on the top of the specimen ( displacements control ) keeping constant the strain rate, or applying a constant stress ( relaxation test ).

A dynamic uniaxial load can be applied as well, following a sinusoidal function in order to study the mechanical response under cyclic loads ( fatigue ). The experimental results employed in this study have been obtained from a static direct tensile test under 
prescribed displacement at different loading rates, keeping constant the strain rate, according to the dimensions of the specimen.

The direct tensile test is performed on two prismatic specimens of asphalt mixture with square base ( Figure $5 \&$ Figure 6) which dimensions are shown in Table 2. The specimens have got an indent of $5 \mathrm{~mm}$ deep, in the central horizontal plane. This indent favours the concentrention of the stresses due to the reduction of the specimen's section, leading the fracture to this point.

\section{Place for Figures $5 \& 6$}

It's generally agreed that temperature influences greatly the asphalt mixture's behavior, so two different temperatures have been considered to characterize the material properties and constitutive values. A temperature of $20^{\circ} \mathrm{C}\left(68^{\circ} \mathrm{F}\right)$ is usually assumed by the standard direct tensile test ( Specimen 1 ).

Additionally, results have been obtained for $8.3^{\circ} \mathrm{C}\left(46.94{ }^{\circ} \mathrm{F}\right)$ to analyse the response of the mixture ( Specimen 2 ) for a colder temperature ( Table 2 ).

Table 2

Specimens' dimensions and temperatures

\begin{tabular}{lcc}
\hline & Specimen 1 & Specimen 2 \\
\hline Height & $140 \mathrm{~mm}$ & $80 \mathrm{~mm}$ \\
Square Base & $50 \times 50 \mathrm{~mm}$ & $60 \times 60 \mathrm{~mm}$ \\
Indent ( Depth ) & $5,0 \mathrm{~mm}$ & $5,0 \mathrm{~mm}$ \\
Temperature & $20,0^{\circ} \mathrm{C}$ & $8,3^{\circ} \mathrm{C}$ \\
\hline
\end{tabular}

\section{2.- Mixture's characteristics}

This work has been developed in the frame of a research project to reach new recycling techniques for pavements tracks and design methods for asphalt mixtures $[15],[16],[17]$. The objective is to formulate a new constitutive model able to characterize the material including conventional or recycled asphalt mixtures. The mix employed in the laboratory tests is composed by a determined fraction of Recycled Asphalt Pavement (RAP), adding an asphalt concrete mix with a maximum aggregate size of $20 \mathrm{~mm}$. (S-20 mix). Table 3.1 
Table 3.1

RAP bitumen properties

\begin{tabular}{lc}
\hline Parameter & $\begin{array}{c}\text { RAP } \\
\text { bitumen }\end{array}$ \\
\hline Content of bitumen $(\%)$ & 4.3 \\
Penetration at $25^{\circ} \mathrm{C}(0,1 \mathrm{~mm})$ & 9 \\
Softening Point R \& B $\left({ }^{\circ} \mathrm{C}\right)$ & 83.0 \\
Penetration index & 0.4 \\
Solubility ( \% waste ) & 0.075 \\
\hline
\end{tabular}

From all de formulations developped, the mixture chosen included a $30 \%$ of RAP and bitumen $80 / 100$.

The recycled material has been characterized, specially considering the bitumen's properties (Table 3.2) which influence on the final mix wants to be observed, and the aggregates added in the mix (Table 3.3)

The experimental tests used taken as reference in this work were made over recycled mixes composed by $30 \%$ RAP with addition of bitumen $80 / 100$.

Table 3.2

Added aggregate size distribution

\begin{tabular}{ll}
\hline $\begin{array}{c}\text { Size } \\
(\mathrm{mm})\end{array}$ & $\begin{array}{c}\text { Aggregate } \\
(\%)\end{array}$ \\
\hline 25 & - \\
20 & - \\
12.5 & - \\
8 & 100 \\
4 & 90.8 \\
2 & 59.6 \\
1 & 38.0 \\
0.5 & 25.8 \\
0.25 & 18.3 \\
0.125 & 14.5 \\
0.063 & 10.5 \\
& \\
Density & $2.679 \mathrm{t} / \mathrm{m}^{3}$ \\
\hline
\end{tabular}

Table 3.3

Added bitumen's properties

\begin{tabular}{ll}
\hline PROPERTIES & $30 \%$ RAP \\
& $\mathrm{B}-80 / 100$ \\
\hline Penetration, $25{ }^{\circ} \mathrm{C}(0,1 \mathrm{~mm})$ & 90 \\
Temperature $\left({ }^{\circ} \mathrm{C}\right)$ & 48.6 \\
Fragility Fraass $\left({ }^{\circ} \mathrm{C}\right)$ & -15 \\
Elastic recuperation $25 \stackrel{\circ}{\circ} \mathrm{C}(\%)$ & - \\
Burning point $\left({ }^{\circ} \mathrm{C}\right)$ & 268 \\
RTFOT & \\
- Mass variation $(\%)$ & 0.32 \\
- Penetration $(\%)$ & 65 \\
- Variation $\mathrm{R} \& \mathrm{~B}\left({ }^{\circ} \mathrm{C}\right)$ & 6.2 \\
- Elastic return, $25{ }^{\circ} \mathrm{C}(\%)$ & - \\
\hline
\end{tabular}

Finally, two different asphalt mixes were obtained with different compositions (Table 4) and mechanical properties. This recycled mixtures have been employed to build a real 
pavement track with the aim of testing the new mixes created employing new dosification methods. New hot and cold recycling techniques and machinery were developed in the same project.

Table 4

\begin{tabular}{ll}
\multicolumn{2}{c}{ Recycled mix composition } \\
\hline & $30 \%$ RAP \\
& B-80/100 \\
\hline Content of bitumen (\%) & 4.5 \\
Relation filler/bitumen ( mass ) & 1.22 \\
Maximum density $\left(\mathrm{t} / \mathrm{m}^{3}\right)$ & 2.508 \\
Porus (\%) & 6.3 \\
\hline
\end{tabular}

\section{3.- Direct tensile test experimental results}

The new recycled mixtures were tested in the laboratory using the Direct Tensile Test as explained before, for different temperatures and loading rates. The load applied corresponds to a prescribed displacement following a monotonic increasing, for different time increments, so that the strain rate changes. The loading rate for the two specimens has been adjusted to keep constant the strain rate as shows Table 5.

Table 5

Prescribed displacements in Direct Tensile Test Vs Strain rate \& Temperature

\begin{tabular}{cccc}
\hline & Specimen 1 & Specimen 2 \\
\hline \multicolumn{2}{c}{ Strain rate $\left(\mathrm{seg}^{-1}\right)$} & $\mathrm{h}=140 \mathrm{~mm}$ & $\mathrm{~h}=80 \mathrm{~mm}$ \\
FAST & $1,19.10^{-4}$ & $1,00 \mathrm{~mm} / \mathrm{min}$ & $0,5700 \mathrm{~mm} / \mathrm{min}$ \\
SLOW & $1,19.10^{-5}$ & $0,10 \mathrm{~mm} / \mathrm{min}$ & $0,0570 \mathrm{~mm} / \mathrm{min}$ \\
QUASI-STATIC & $1,19.10^{-6}$ & $0,01 \mathrm{~mm} / \mathrm{min}$ & $0,0057 \mathrm{~mm} / \mathrm{min}$ \\
\hline
\end{tabular}

Three different strain rates have been chosen to study the asphalt mixture's response in front of the loading rate variable and for a temperature variation. The response observed is plotted as strenght - displacement diagram (Figure 7) avoiding stress and strain definitions because the section and the height of the specimen are variable magnitudes during the test and difficult to measure.

Place for Figure 7 
The asphalt mixture increases its stresses when the prescribed displacement grows, until it reaches a maximum strenght point. Further, the material loses stress and relaxes showing a softening behaviour after the maximum is reached.

The temperature definetely influences in the response observed, increasing the maximum strenght developed by the material as expected, and reducing the range of displacements in the charge - relaxation process.

The most important item provided by the laboratory tests is the strain rate dependency shown by the asphalt's behavior, in relation to the curve and to the maximum strenght reached.

\section{4.- Calibration of the model}

To calibrate de model a numerical modelation of the two experimental specimens has been designed. Specimen's symmetric geometry have been considered to simplify the problem and increase the precision of the results with denser mesh, prescribing the suitable boundary conditions in the symetry axes as shown in Figure 8.

\section{Place for Figure 8}

The numerical domains perform the indent as a slightly round boundary to avoid angular edges which can create non expected distorsions or concentration of stresses. This reduction of the section in the horizontal symmetry axe looks forward to reproduce the concentration of stresses in the real test, that leads to the failure of the material.

The simulation of the laboratory tests allows us to obtain the constitutive parameters, for the three strain rates and two temperatures, chosen as reference ( Table 6.1 \& Table 6.2

) geometric relation between the three Young modulus and viscosities obtained for each strain rate, the two constants from the strain rate expressions $-\mathrm{K}_{\mathrm{E}}, \mathrm{K}_{\xi}-$ can be determined, for every temperature as explained in equations (1),(2) 


\section{Table 6.1}

Constitutive values for temperature $20,0^{\circ} \mathrm{C}$

\begin{tabular}{|c|c|c|c|c|c|}
\hline & $\begin{array}{l}\text { Strain rate } \\
{\left[\mathrm{seg}^{-1}\right]}\end{array}$ & $\begin{array}{c}\text { Young } \\
\text { Modulus } \\
{\left[\mathrm{KN} / \mathrm{m}^{2}\right]}\end{array}$ & $\begin{array}{c}\text { Yield Stress } \\
{\left[\mathrm{KN} / \mathrm{m}^{2}\right]}\end{array}$ & $\begin{array}{l}\text { Viscosity } \\
{\left[\mathrm{KN} \cdot \mathrm{s} / \mathrm{m}^{2}\right]}\end{array}$ & $\begin{array}{c}\text { Fracture } \\
\text { Energy } \\
{[\mathrm{KN} / \mathrm{m}]}\end{array}$ \\
\hline FAST & $1,20.10^{-4}$ & $1,40.10^{6}$ & 40 & $0,175.10^{6}$ & 0,021 \\
\hline SLOW & $1,20.10^{-5}$ & $0,45 \cdot 10^{6}$ & 40 & $0,80 \cdot 10^{6}$ & 0,018 \\
\hline \multirow[t]{4}{*}{ Q_STATIC } & $1,20.10^{-6}$ & $0,15 \cdot 10^{6}$ & 40 & $4,00.10^{6}$ & 0,017 \\
\hline & Fast / Slow & 3,111 & & 0,2125 & \\
\hline & Slow/Q_static & 3,000 & & 0,2000 & \\
\hline & $\mathrm{K}_{\mathrm{E}}$ & 3,056 & $\mathrm{~K}_{\xi}$ & 0,206 & \\
\hline
\end{tabular}

Table 6.2

Constitutive values for temperature $8,3^{\circ} \mathrm{C}$

\begin{tabular}{lllccc}
\hline & $\begin{array}{c}\text { Strain rate } \\
{\left[\mathrm{seg}^{-1}\right]}\end{array}$ & $\begin{array}{c}\text { Young } \\
\text { Modulus } \\
{\left[\mathrm{KN} / \mathrm{m}^{2}\right]}\end{array}$ & $\begin{array}{c}\text { Yield Stress } \\
{\left[\mathrm{KN} / \mathrm{m}^{2}\right]}\end{array}$ & $\begin{array}{c}\text { Viscosity } \\
{\left[\mathrm{KN} \cdot \mathrm{s} / \mathrm{m}^{2}\right]}\end{array}$ & $\begin{array}{c}\text { Fnergy } \\
{[\mathrm{KN} / \mathrm{m}]}\end{array}$ \\
\hline FAST & $1,20.10^{-4}$ & $1,65.10^{6}$ & 60 & $0,20.10^{6}$ & 0,020 \\
SLOW & $1,20.10^{-5}$ & $1,50.10^{6}$ & 60 & $1,30.10^{6}$ & 0,022 \\
& $1,20.10^{-6}$ & $1,20.10^{6}$ & 60 & $7,00.10^{6}$ & 0,016 \\
& Fast/Slow & 1,100 & & 0,1538 & \\
& Slow/Q_static & 1,250 & & 0,1857 & \\
& & & & & \\
& $\mathrm{~K}_{\mathrm{E}}$ & 1,173 & $\mathrm{~K}_{\xi}$ & 0,170 & \\
\end{tabular}

The Poisson's ratio is assumed as constant as well as the fracture energy. The Yield stress is also assumed as constant for each temperature, but the range of elastic behavior is not much significant. The prescribed displacements exceeds this elastic limit easily, so the response is practically viscoplastic in the whole range of displacements.

Once the constants have been calibrated, the Young modulus and viscosity are determined by the model in the nonlinear range (1),(2) for a stationary state of temperature.

$$
\begin{array}{ll}
E(\dot{\varepsilon})=0,15.10^{6} \cdot[3,056]^{\log \left(\frac{\dot{\varepsilon}}{1,2.10^{-6}}\right)} & E(\dot{\varepsilon})=1,20.10^{6} \cdot[1,173]^{\log \left(\frac{\dot{\varepsilon}}{1,2.10^{-6}}\right)} \\
\xi(\dot{\varepsilon})=4,00.10^{6}[0,206]^{\log \left(\frac{\dot{\varepsilon}}{1,2.10^{-6}}\right)} & \xi(\dot{\varepsilon})=7,0.10^{6} \cdot[0,170]^{\log \left(\frac{\dot{\varepsilon}}{1,2.10^{-6}}\right)}
\end{array}
$$


where $\dot{\varepsilon}_{0}=1,20.10^{-6}$ is the reference strain rate for the experiments

$\mathrm{E}_{0}, \xi_{0}$ are the corresponding Young modulus and viscosity at every temperature. According to the model formulation the Young modulus is a strain rate function obtained at every calculation point, so it's not a prescribed value.

The strain rate function for the Young modulus is monotonically increasing curve, showing a dicreasing slope with the strain rate, tending to a constant value ( Figure 9.1 ). That means the stifness of the material can grow indefinitely.

\section{Place for Figure 9.1}

The curve obtained for the Young modulus shows a high dependence on the temperature as expected. For a colder environment the stiffness is higher but when the strain rate grows this difference tends to zero.

The evolution of the viscosity parameter included in the viscoplastic model [1] with the strain rate is represented in Figure 9.2. It shows how the viscosity variation is higher for low strain rates and viceversa. This parameter is also obtained by the model at every calculation point during the modelation process, so it's not a prescribed value.

Place for Figure 9.2

On the other hand, the influence of the temperature is not very important. The functions found by the calibration process are similar altough the numerical results are quite sensitive to the viscosity.

As explained in Table 7 this constitutive parameter provides a regularization between viscoelasticity and plasticity models, so to validate the viscoplastic model, numerical simulations have been made with intermediate and extreme values of the parameter $\xi$ constant.

Table 7

Viscoplastic behavior limits

\begin{tabular}{lcc}
\hline $\begin{array}{l}\text { Viscosity } \\
{\left[\mathrm{kN} \cdot \mathrm{s} / \mathrm{m}^{2}\right]}\end{array}$ & Plastic strain rate & $\begin{array}{l}\text { Behavior } \\
\text { expected }\end{array}$ \\
\hline$\xi=20,0 \cdot 10^{6}$ & $\dot{\varepsilon}^{v p}=0$ & $\approx$ Elastic \\
$\xi=0,80 \cdot 10^{6}$ & $\dot{\varepsilon}^{v p}(12)$ & Viscoplastic \\
\hline
\end{tabular}




$$
\xi=0,01 \cdot 10^{6} \quad \dot{\varepsilon}^{v p}=\dot{\varepsilon}^{p} \quad \approx \text { Plastic }
$$

The simulation of the extreme behavior in the presented model have been made for a given strain rate ( Slow Test $\Rightarrow \dot{\varepsilon}=1,20.10^{-5} \mathrm{seg}^{-1}$ ) and constant temperature. The results are presented in Figure 10

Place for Figure 10

As observed, for a low viscosity a plastic response is obtained. On the other hand, for a high viscosity value the behavior observed is tipically viscoelastic tending to an elastic response.

\section{5.- Experimental results Vs Numerical results}

The described model has been used for the numerical simulation of the asphaltic material response. The results were compared with experimental test for the corresponding two temperatures and three strain rates named FAST, SLOW and QUASI-STATIC test. The results for the constitutive parameters considered in Table 6.1 and Table 6.12 are shown in Figure 11.1, 11.2, 11.3.

Place for Figure 11.1

The numerical approximation to the experimental curves is fairly good for the constitutive values and expressions adopted, taking into account the high level of variation in the material's respose, even for a fixed strain rate and temperature.

Place for Figures $11.2 \& 11.3$

These curves have been calibrated for three strain rates (FAST, SLOW and QUASISTATIC) and show a continuity in the response obtained with the model. The simulation process can be generalised for any strain rate value obtaninig a serie of strenght - displacement curves for a determined asphalt mixture at a fixed temperature as shown in Figure 12.

Place for Figures 12 


\section{APPLICATION OF THE MODEL TO A PAVEMENT STRUCTURE UNDER DYNAMIC LOAD}

\section{1.- Experimental track. Geometry and mechanical parameters}

The proposed model has been applied to the simulation of a real pavement structure. In the frame of PARAMIX project a stretch was built to test the improvements reached in the research task, about the new asphaltic mixtures dosification methods, work techniques and machinery for cold and hot recycled mixtures.

\section{Place for Figure 13.1}

The track selected for the experimental tests was built in Spain. To be precise, the C58 track is placed between Terrassa and Manresa, next to Barcelona (Figure 13.1 \& Figure 13.2). Some subtracks were built employing the technical improvements developed for cold and hot recycling.

\section{Place for Figure 13.2}

The pavement was conformed by multilayered system composed by two asphalt layers over granular basis. One asphalt layer placed over the granular base made of preexistent asphalt, and another one placed over made of recycled asphalt mixture. The geometry and the mechanical parameters considered for the pavement are detailed in Table 8 .

Table 8

Pavement layers.- Thickness and Young modulus

\begin{tabular}{lcc}
\hline & $\begin{array}{c}\text { Thickness } \\
(\mathbf{c m})\end{array}$ & $\begin{array}{c}\text { Young } \\
\text { modulus ( MPa })\end{array}$ \\
\hline Recycled Asphalt layer & 15,0 & 5.000 \\
Old Asphalt layer & 15,0 & 5.000 \\
Granular base & 20,0 & 530 \\
Granular subbase & 50,0 & 200 \\
\hline
\end{tabular}

\section{2.- Determinant variables of the problem.}

To measure the asphalt mixture's response some measurement instruments were implemented. Some tests of deflection were made during project's lifetime and 
horizontal strains were measured in the interphase between the old and recycled asphalt layers, for different temperatures.

The basic variable considered in this study is the horizontal strain produced in the limit between the two asphalt layers. Two situations have been considered in this work, taking into account the possibility that the material cracks. In this case, the stress-strain response is different that in case of continuum material. In fact, the microcracks existing in the pavement and its propagation are the main cause of the failure of the structure. Both cases have been modeled employing the news purposed model.

In the experimental pavement track six strain gauges have been placed in the interphase to measure horizontal strains in longitudinal way, in continuum and cracked pavement. Three of them have been embedded between de old and recycled layer. The other three guages have been placed at the top of a fissure $5 \mathrm{~mm}$ wide and $5 \mathrm{~cm}$ deep, cut in the surface of the old asphalt layer, to simulate de non-continuum material. The location and gap between the gauges is shown in Figure 14.1 \& Figure 14.2.

Place for Figure 14

The subtrack considered for the simulation was built employing hot recycling techniques and mixtures. The execution process of the cold recycled pavement includes the old pavement demolition, the dosification of the new mixture and the collocation of the recycled layer, simultaneously. For this reason, the installation of the sensors takes place after the recycled asphalt layer has been executed.

In the subtracks built with hot recycled mixtures the gauges are installed before the new asphalt layer is extended, once the upper part of the old pavement has been demolished, and the crack made ( Figure 15 )

\section{Place for Figure 15}

The gauges are installed over a Kapton's film to ensure a plane surface for the sensor. This film is embedded in a small amount of mixture made of sand and bitumen of $1 \mathrm{~cm}$ thick over and under the gauge, to protect the sensor and to ensure a good adherence with the recycled layer over. ( Figure 16 )

Place for Figure 16 
The dynamic load is applied using a roller passing over the surface of the recycled pavement layer structure. Several measurements of the horizontal strains have been made for different speeds of the roller, with the aim of studying the influence of this variable in the response observed ( Figure 17)

\section{Place for Figure 17}

As a summary this work analyses the pavement's response under dynamic loads assimilable to service loads the structure will hold during its lifetime. The analysis has considered three different variables as determinant in the pavement's short term behavior (Table 9). The proposed model has been employed to simulate the experimental behaviour observed.

Table 9

Determinant variables in the study

\begin{tabular}{ccc}
\hline Variables & \multicolumn{2}{c}{ Cases } \\
\hline Temperature & $20,0^{\circ} \mathrm{C}$ & $8,3 \mathrm{C}$ \\
Asphalt pavement & Continuum & Cracked \\
Roller speed & High & Low \\
\hline
\end{tabular}

The deformation mechanism which takes places at every point in the interphase between the asphalt layers is a compression-tension cycle corresponding to the pass of one axe of the compactor roller. The load produces a maximum tensile stress in the vertical plane of the application point, and compression stresses next to it.

The sensor measures the horizontal strain's evolution during the loading process, offering a strain-time curve produced by de pass of one roller with two axes. So the curves are characterised by seven critical points ( Figure 18 )

Place for Figure 18

- Maximum compression stress (B,D) when the roller approaches to the gauge.

- Maximum tension stress ( C,E ) when the roller is over the point and produces an stretching in the interphase between the two layers 
- Start ( A ) and end ( G ) of the deformation process with a previous point of stabilization of the horizontal strain ( F ).

This curves have been obtained periodically, for different temperatures amb climatic conditions, speeds of the roller and type of pavement ( continuous and cracked ).

\section{3.- Numerical modelation. Geomtery and parameters}

The proposed model has been applied to simulate this strain-time curves observed in a real track. A numerical simulation has been designed, reproducing the dimensions of the layered system and the location of the gauges presented, and the mechanical parameters mentioned above.

Additionally, some boundary conditions have been assumed to complete the numerical domain employed in the simulation (Figure 19.1):

Place for Figure 19.1

- Far away enough from the roller position, the effects of the load are negligible, so the horizontal strain and displacements are not significant and prescribed to zero.

- For a granular subbase thick enough vertical displacements are assumed to be zero.

The cracked pavement is also simulated by a crack in the old asphalt layer. The "crack" is $5 \mathrm{~cm}$ deep as in the real pavement and $1 \mathrm{~cm}$ wide, a bit more than the real one, looking for simplicity and clearness of the results ( Figure 19.2 )

$$
\text { Place for Figure } 19.2
$$

A concentration of the strains next to the crack is expected, so a calculation point has been considered on the top of if. This will permit us to reproduce the response of the structure when the material it is and it's not continous, verifying the results obtained with the model in both cases. 


\section{4.- Numerical Vs Experimental results}

The range of the results observed is significant and for this reason maximum and minimum values have been taken into account in the experimental data.

The strain - time response produced for one wheel over the pavement has been simulated and compared with the points B \& $\mathrm{C}$ of the esperimental results. A cycle of compression - traction - compression is reproduced by the model for two different speeds ( Low $\mathrm{V}=4,52 \mathrm{Km} / \mathrm{h}$ and High $\mathrm{V}=10,59 \mathrm{Km} / \mathrm{h}$ ) and for a temperature of $8,3^{\circ} \mathrm{C}$.

The amplitudes of the horizontal strain in compression and tension approximates fairly well the experimental gap between maximum and minimum values Figure 20.1 \& Figure 20.2

Place for Figures $20.1 \& 20.2$

The numerical results provides a horizontal strains distribution next to the crack where it can be appreciated the tensions in the interphase between the two asphalt layers, caused by the loading roller. These tensions advance with the load and reaches the maximum values over the fissure.

Place for Figure 21.1

The horizontal strains distributions are presented next to the fissure (continuum pavement) and over (cracked pavement) in Figure 21.1 \& Figure 21.2

Place for Figure 21.2

\section{SUMMARY AND CONCLUSIONS}

A new viscoplastic model has been developped for the simulation of the asphalt mixtures' mechanical behaviour, taking into account the strain rate dependancy of the material's response observed in the experimental results.

The new variable influences in the constitutive parameters in a different way. The strain rate dependancy is significant for the Young modulus and for the viscosity. Mathematical expressions for both parameters have been formulated and calibrated according to experimental results in the laboratory with asphalt specimens. 
The model shows a good precision in the simulation of the material response, for different temperatures and rates of loading.

Once the model has been calibrated and the material's properties characterised, the model has been applied to simulate the mechanical behaviour of a multilayered sytem conformed by two layers of cold recycled and old pavement and two granular layers.

The test has been made taking into account different parameters to study the influence of each of them over the system response, and to check the capacity of the model to simulate the behaviour observed in the real track.

The curves obtained with the model show a good approximation to the experimental curves in the critical points, considering de high degree of variation of these ones, and the complexity of the problem

\section{ACKNOWNLEDGEMENTS}

The authors want sincerely acknowledge the financial support from the UE GROWTH programm, as well as the the Research and development program from de Spanish Ministry of Education. We also highly appreciate the technical support of the Transport engineering department of the UPC University.

\section{REFERENCES}

[1] Barbat, A., Oller, S., Oñate, E. and Hanganu, A. (1997) “Viscous Damage Model for Timoshenko Beam Structures." International Journal of Solids and Structures. Vol. 34, No 30 pp. $3953-3976$.

[2] Lubliner, J., Oliver, J., and Oñate, E. (1989) “ A Plastic Damage Model for Concrete. "International Journal of Solids and Structures, Vol 25, No 3 pp. $299-326$

[3] Dr. Owen, J., Hinton, E. (1980), Second Reprint (1986) "Finite Elements in Plasticity. Theory and Practice", Swansea U.K.

[4] Yang H. Huang. (1993), "Pavement Analysis and Design", Englewoods Cliff, New Jersey ( EE UU )

[5] Zienkiewicz, O. and Taylor, R. (1989), “The finite element method". McGrawHill, Vol I y II.

[6] Kuo-Neng G. Chang, Jay N. Meegoda. (1997), “ Micromechanical Simulation of Hot Mix Asphalt “. Journal of engineering mechanics, 495-503 
[7] George K. Chang, Jay N. Meegoda. (1999), “ Micromechanical Model for Temperature Effects of Hot-Mix Asphalt Concrete". Transportation Research Record 1687

[8] Kamyar C, Mahboub et al. " Evaluation of temperature responses in concrete pavement “. Journal of transportation engineering ASCE (May - June 2004) 395-401

[9] Seong-Wan, Park et al. "Effect of stress-dependent modulus and Poisson's ratio on structural responses in thin asphalt pavements". Journal of transportation engineering ASCE (May - June 2004) 387-394

[10] Gordon D. Airey et al. "Linear rheological behaviour of bituminous paving materials“. Journal of transportation engineering ASCE (May - June 2004) 212-220

[11] Erkens, Sandra. "Het gedrag van asfalt". Delft university press. (2002)

[12] Perez-Foguet, A., Rodríguez-Ferran A. and Huerta, A. (2000) “ Numerical differentiation for local and global tangent operators in computational plasticity " Computer Methods in Applied Mechanics and Engineering Vol. 189, No 1, pp. 277-296

[13] Celentano, Diego Javier. Oller, S. and Oñate, E. (1996) “ A coupled Thermomechanical Model for the Solidification of Casted Metals "International Journal of Solids and Structures. Vol 33, No 5, pp. $647-673$

[14] Eyad Massad et al. " Microstructual viscoplastic continuum model for permanent deformation in asphalt pavements ". Journal of transportation engineering ASCE ( January 2005) 48-56

[15] Pèrez Jiménez, F., Rodríguez, M., De Visscher, J., Vanelstraete, A. De Bock, L. (2004). "Design and performance of hot mix asphalts with high percentages of reclaimed asphalt. Approach followed in the PARAMIX project". Eurasphalt \& Eurobitume Congress, pp. 447-459. Vienna (Austria).

[16] Vanelstraete, A., De Visscher J., Fernández, M., Sotos, J.A., De Bock, L. (2004). "Selection of binders for asphalt mixes with reclaimed asphalt as studied in the PARAMIX Project." Eurasphalt \& Eurobitume Congress, pp. 612-623. Vienna (Austria).

[17] Pérez Jiménez, F., Miró Recasens, R., Martínez, A. (2004) “Characterisation and design of hot-recycled bituminous mixtures." International RILEM Conference on the use of recycled materials in building and structures, pp. 23-30. Barcelona (Spain) 


\section{FIGURES CAPTION}

Figure 1: Original rheological scheme for the viscoplastic model purpose

Figure 2: Rheological scheme for the Viscoplastic model with $\mathrm{E}, \xi$ strain rate dependent

Figure 3: Scheme of the constitutive model's algorithm.Constitutive variables and parameters involved

Figure 4: Direct tensile test set-up

Figure 5: Direct tensile test scheme

Figure 6: Asphalt mixture specimens

Figure 7: Strenght - Displacements response. Direct Tensile Test

Figure 8: Domains for numerical simulation. Specimen $1\left(20^{\circ} \mathrm{C}\right) \&$ Specimen $2\left(8,3^{\circ} \mathrm{C}\right)$

Figure 9.1: Young modulus Vs Strain rate

Figure 9.2: Viscosity Vs Strain rate

Figure 10: Viscoplastic behavior limits. Response obtained in relation to the viscosity parameter

Figure 11.1: Numerical Vs Experimental test. FAST Test. $\dot{\varepsilon}=1,2.10^{-4} \mathrm{sec}^{-1}$

Figure 11.2: Numerical Vs Experimental test. FAST Test. $\dot{\varepsilon}=1,2.10^{-5} \mathrm{sec}^{-1}$

Figure 11.3: Numerical Vs Experimental test. FAST Test. $\dot{\varepsilon}=1,2.10^{-6} \mathrm{sec}^{-1}$

Figure 12: Evolution of the material's response with Strain rate. Temperature $8,3^{\circ} \mathrm{C}$

Figure 13.1: Experimental tracks' location ( PARAMIX ). Barcelona, Spain

Figure 13.2: Experimental tracks' location ( PARAMIX ).

Track C-58 Terrassa ( Barcelona, Spain )

Figure 14.1: Distance (m) and position of the six strain gauges

Figure 14.2: Location of the six strain gauges

Figure 15: Cracked and continum asphalt layer

Figure 16: Embedded gauge ( detail )

Figure 17: Pavement structure loading phase

Figure 18: Horizontal strain - Time evolution. Experimental curve. Critical points

Figure 19.1: Pavement structure and gauges location. Boundary conditions and dimensions

Figure 19.2: Pavement structure and gauges location

Figure 20.1: Numerical Vs experimental response. $\mathrm{T}=8,3{ }^{\circ} \mathrm{C}$.

Cracked pavement. Low speed of loading

Figure 20.1: Numerical Vs experimental response. $\mathrm{T}=8,3{ }^{\circ} \mathrm{C}$.

Cracked pavement. High speed of loading

Figure 21.1: Horizontal strains distribution in Continum pavement.

Interphase between the asphalt layers

Figure 21.1: Horizontal strains distribution in cracked pavement. Interphase between the asphalt layers 


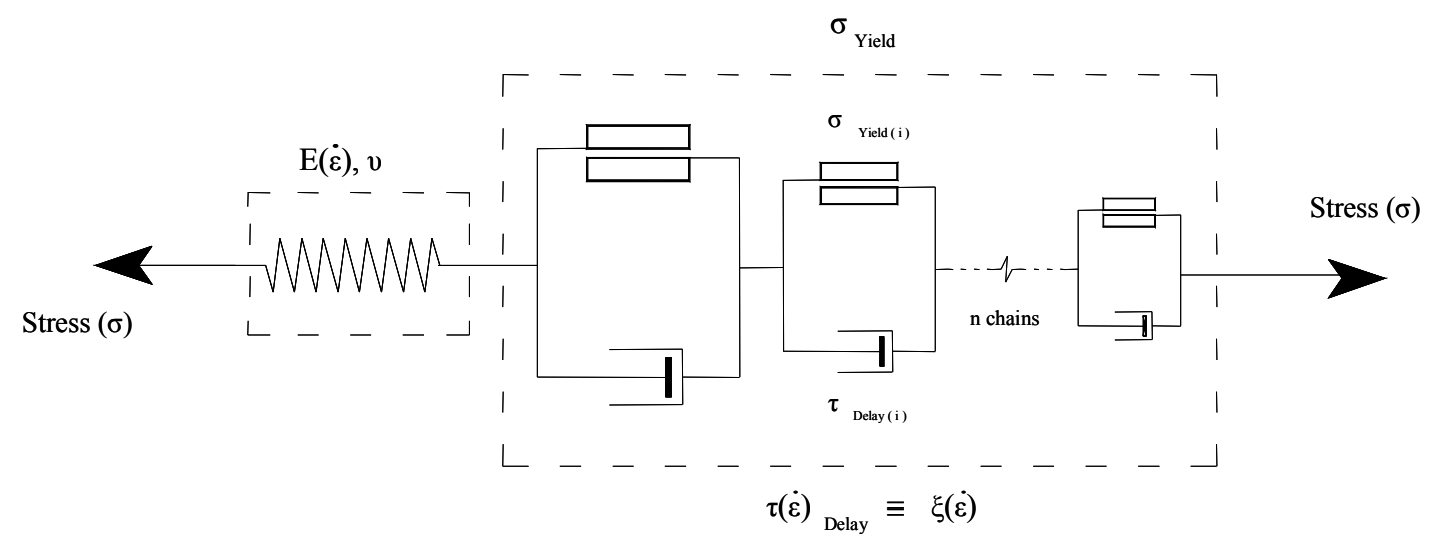

Figure 1. - Original rheological scheme for the viscoplastic model purpose

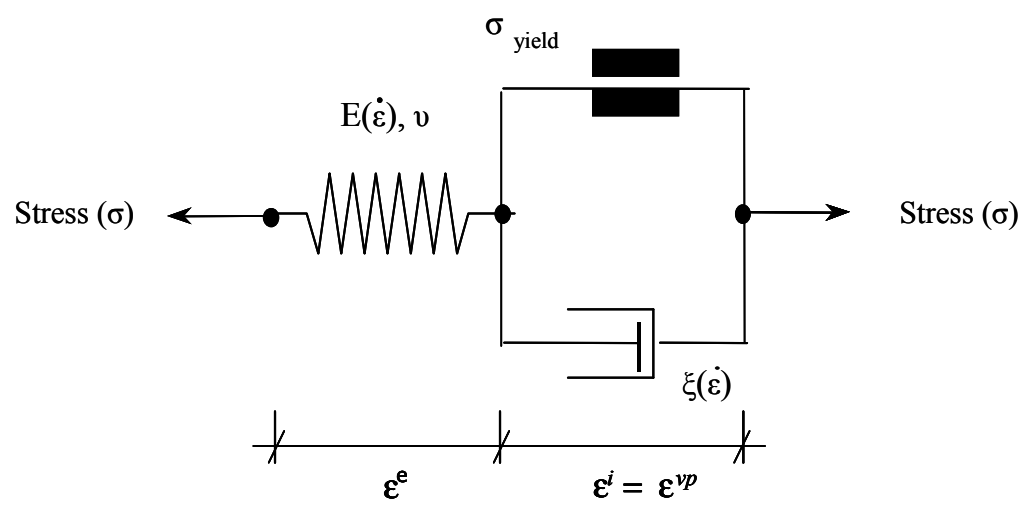

Figure 2. - Rheological scheme for the

Viscoplastic model with E, $\xi$ strain rate dependent 
Scheme of the constitutive model's integration algorithm

\section{Initial}

Data
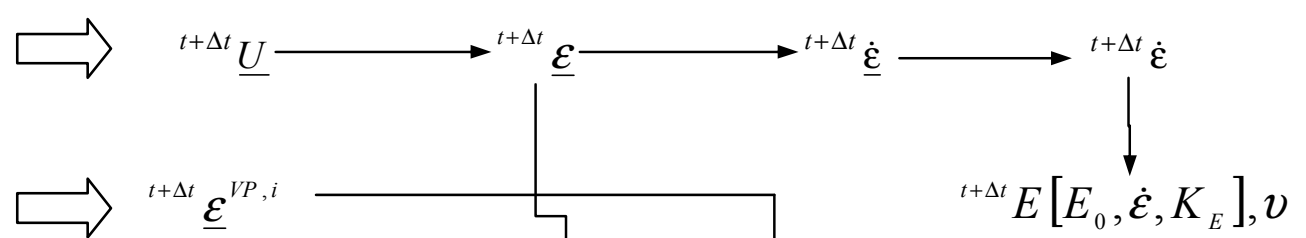

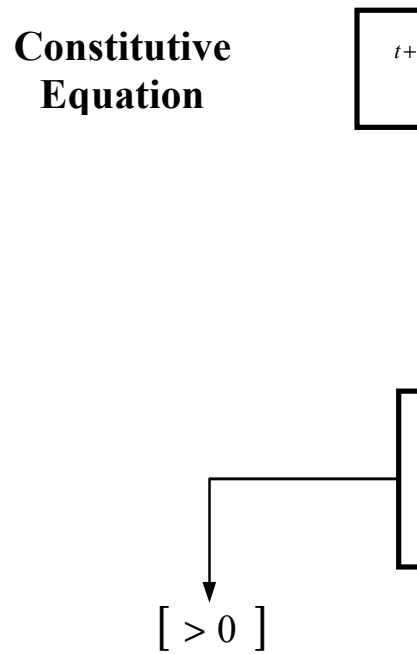

VISCOPLASTIC RESPONSE

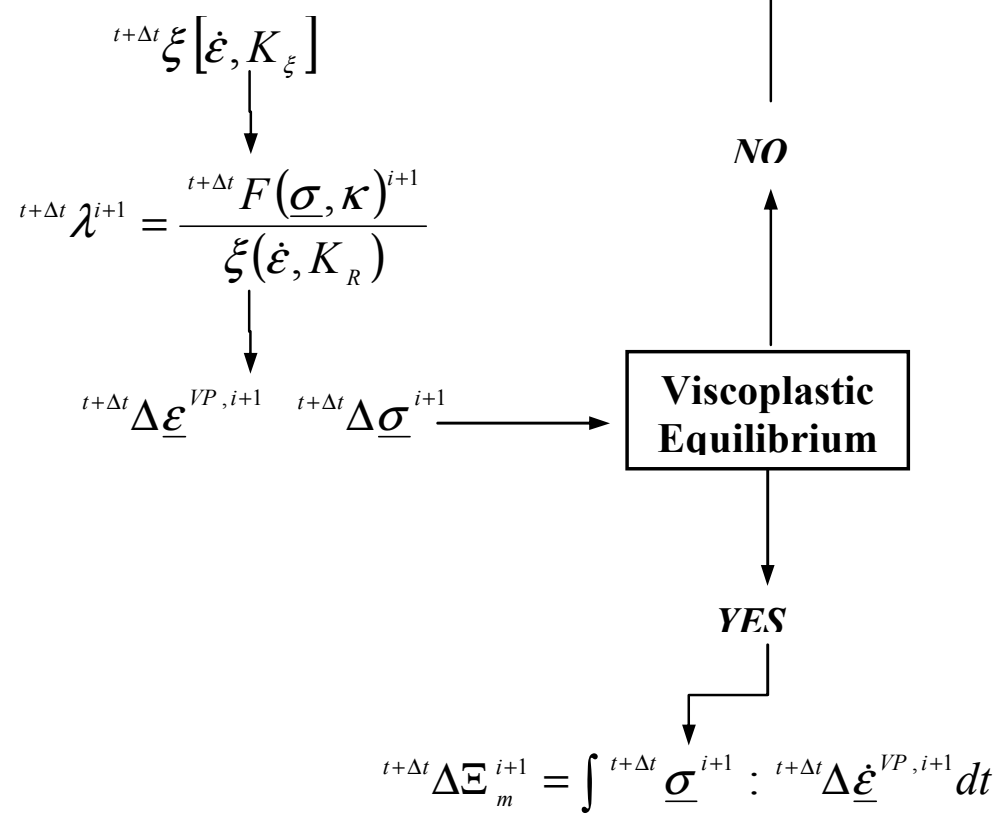

Energy dissipated

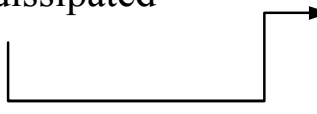

Figure 3. - Scheme of the constitutive model's algorithm

Constitutive variables and parameters involved

\section{ELASTIC} RESPONSE 


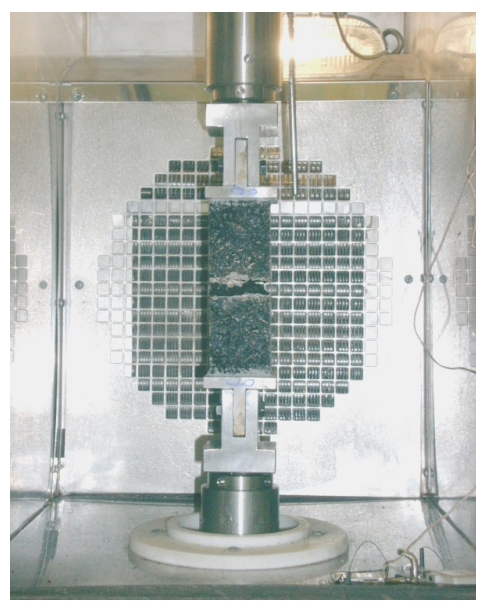

Figure 4.- Direct tensile test set-up

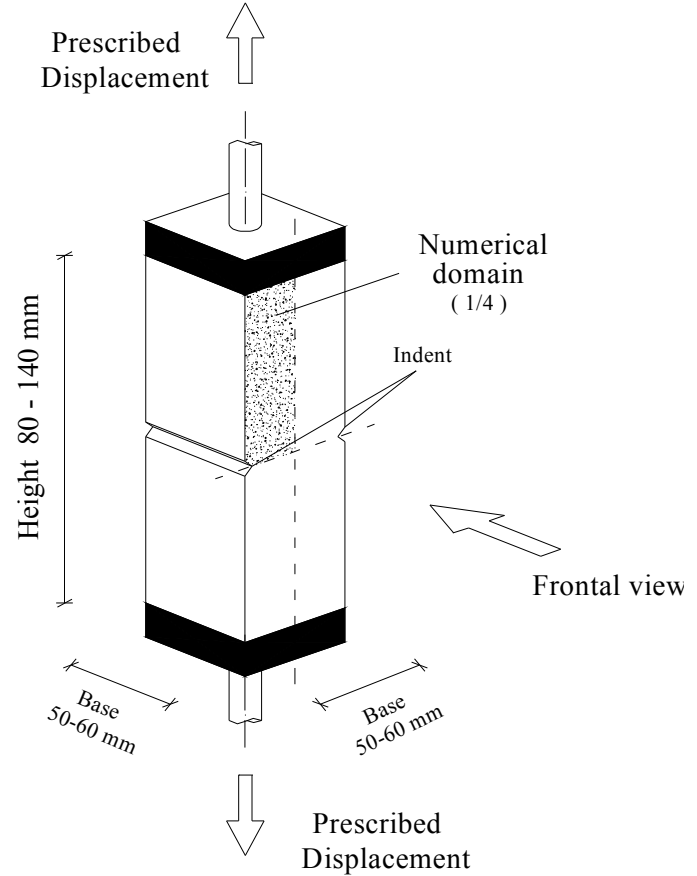

Figure 5.- Direct tensile test scheme

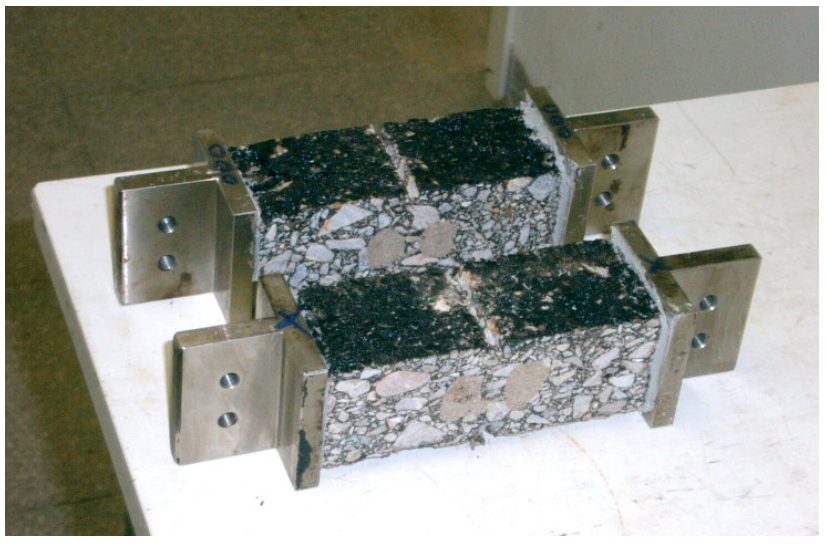

Figure 6.- Asphalt mixture specimens 

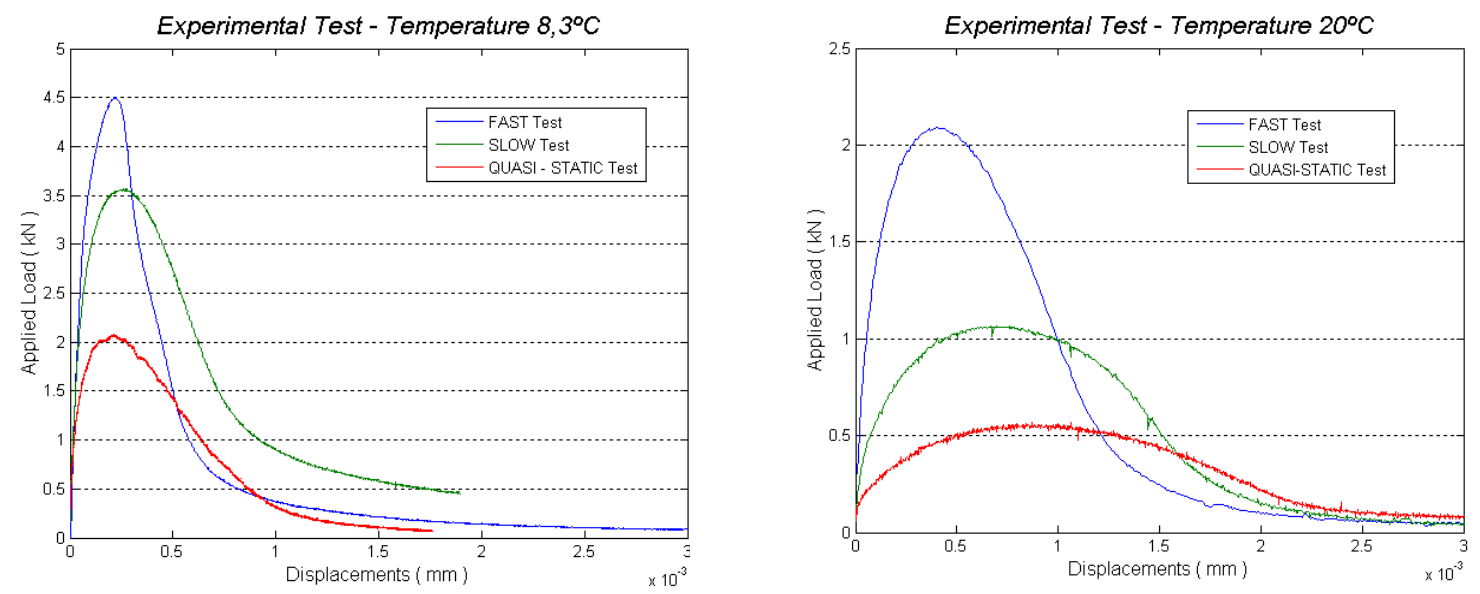

Figure 7.- Strenght - Displacements response. Direct Tensile Test

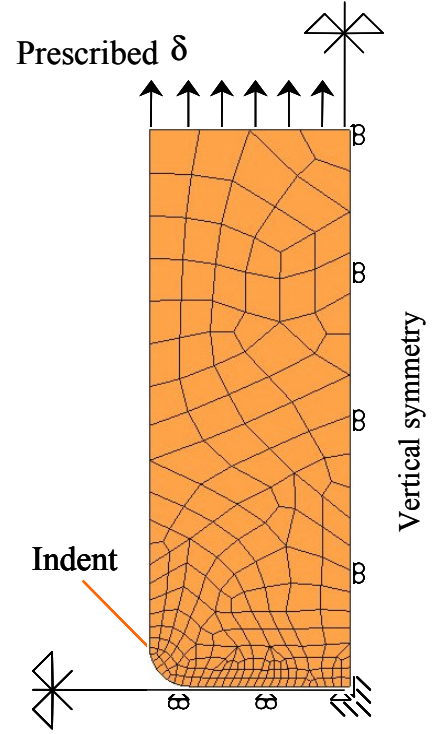

Horizontal symmetry

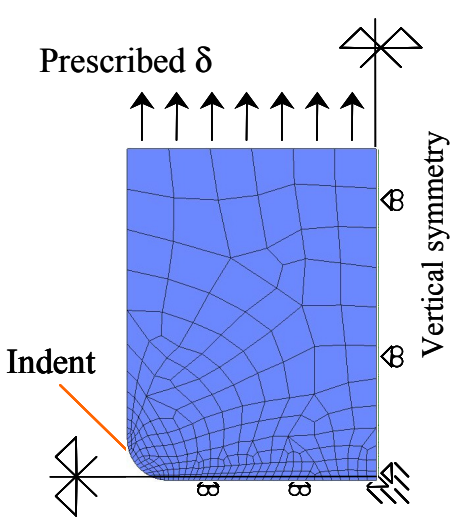

Horizontal symmetry

$2^{\text {nd }}$ Specimen

${ }^{1 \text { st }}$ Specimen

Figure 8.- Domains for numerical simulation.

Specimen $1\left(20^{\circ} \mathrm{C}\right) \&$ Specimen $2\left(8,3^{\circ} \mathrm{C}\right)$ 


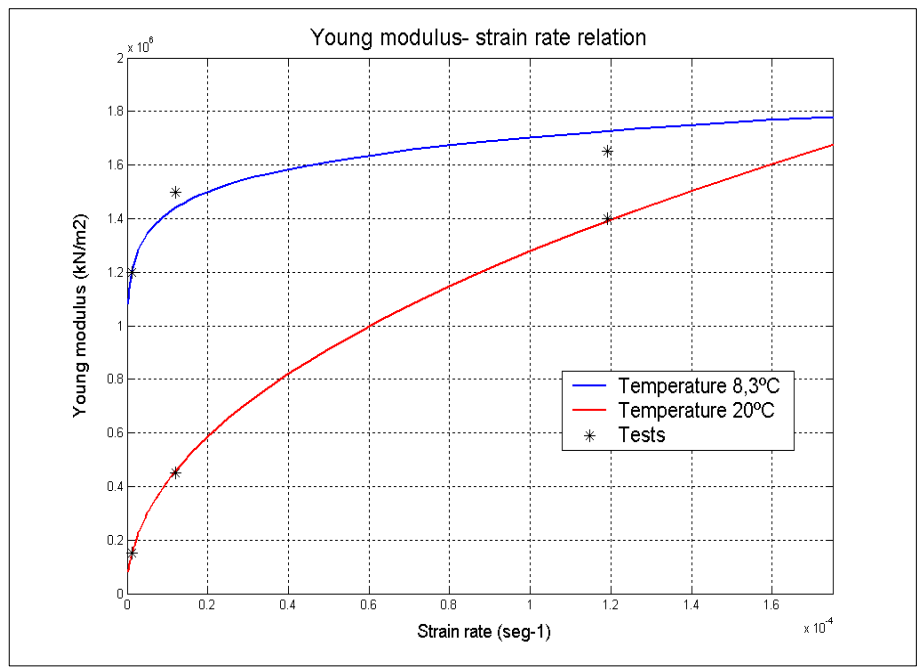

Figure 9.1.- Young modulus Vs Strain rate

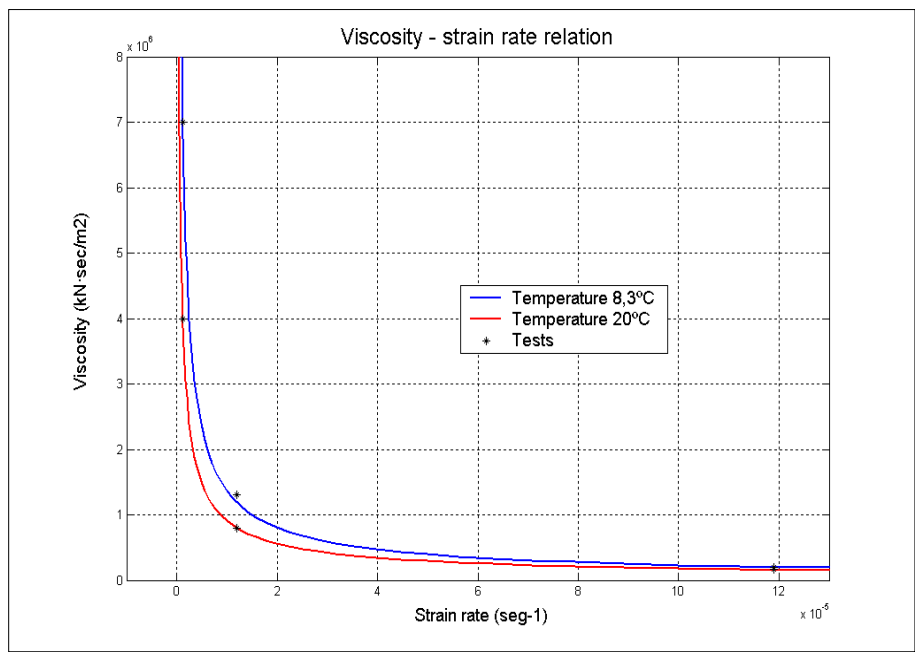

Figure 9.2.- Viscosity Vs Strain rate

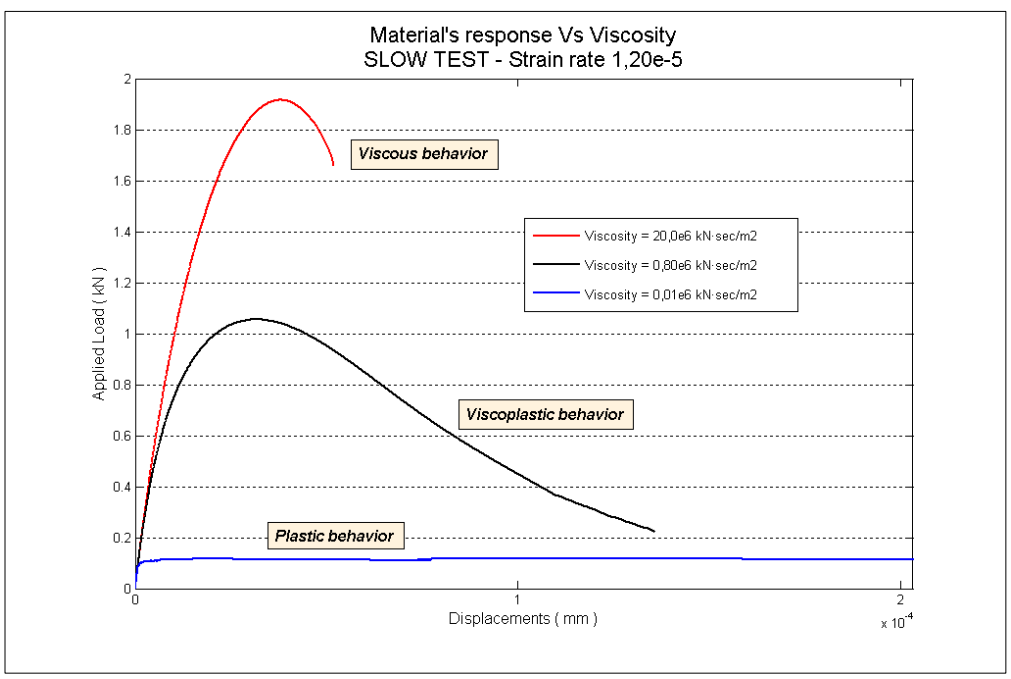

Figure 10. - Viscoplastic behavior limits

Response obtained in relation to the viscosity parameter 


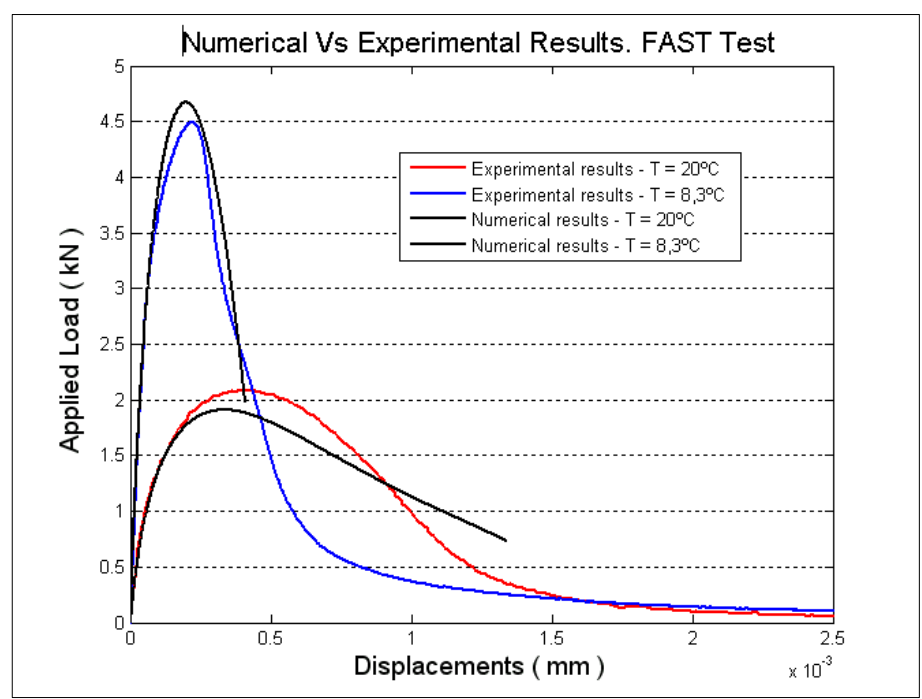

Figure 11.1.- Numerical Vs Experimental test

FAST Test. $\dot{\varepsilon}=1,2 \cdot 10^{-4} \sec ^{-1}$

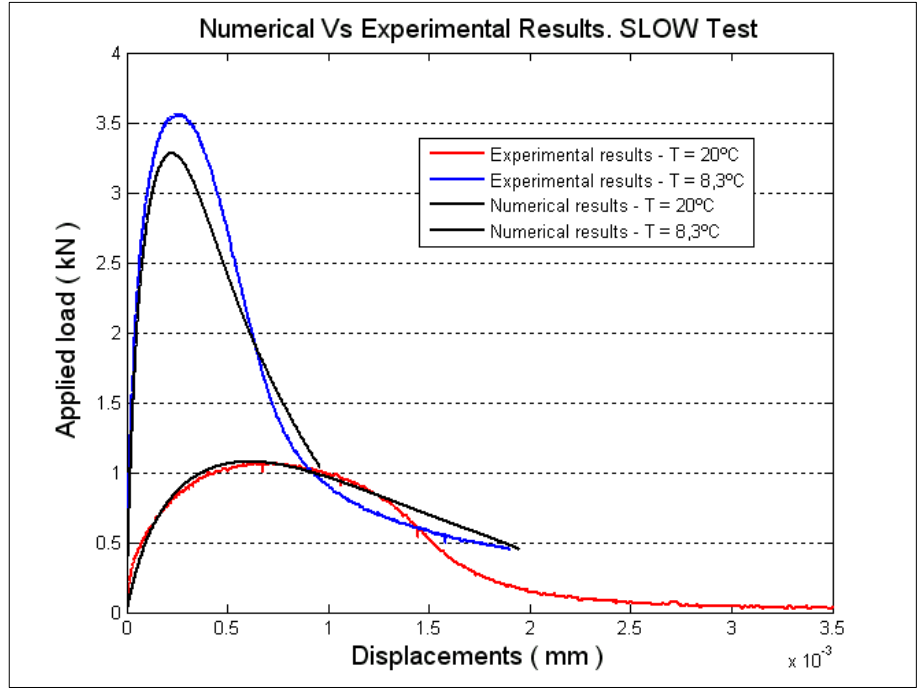

Figure 11.2.- Numerical Vs Experimental test

SLOW Test. $\dot{\varepsilon}=1,2.10^{-5} \sec ^{-1}$

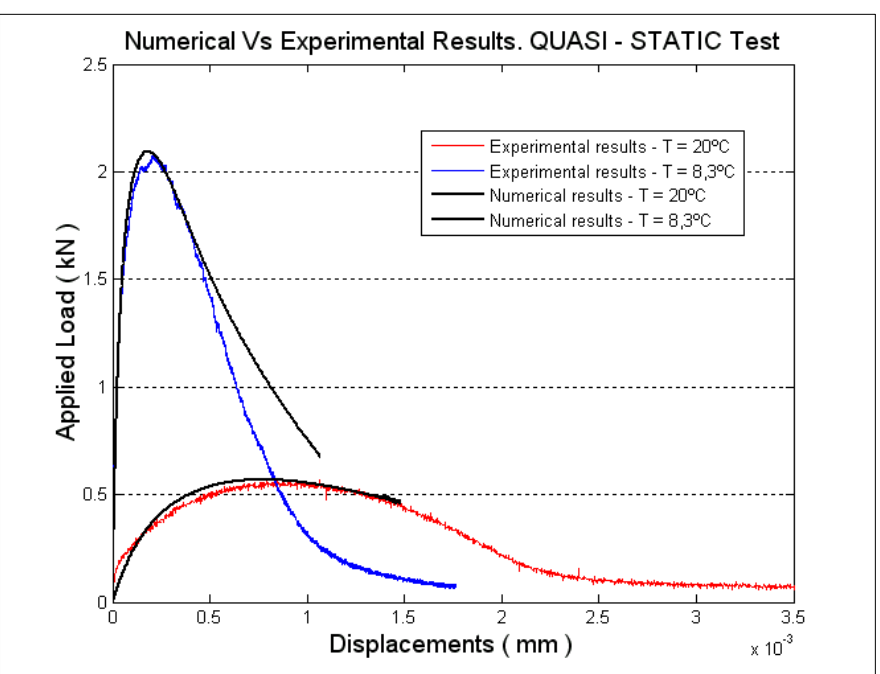

Figure 11.3.- Numerical Vs Experimental test QUASI-STATIC Test. $\dot{\mathcal{\varepsilon}}=1,2 \cdot 10^{-6} \mathrm{sec}^{-1}$ 


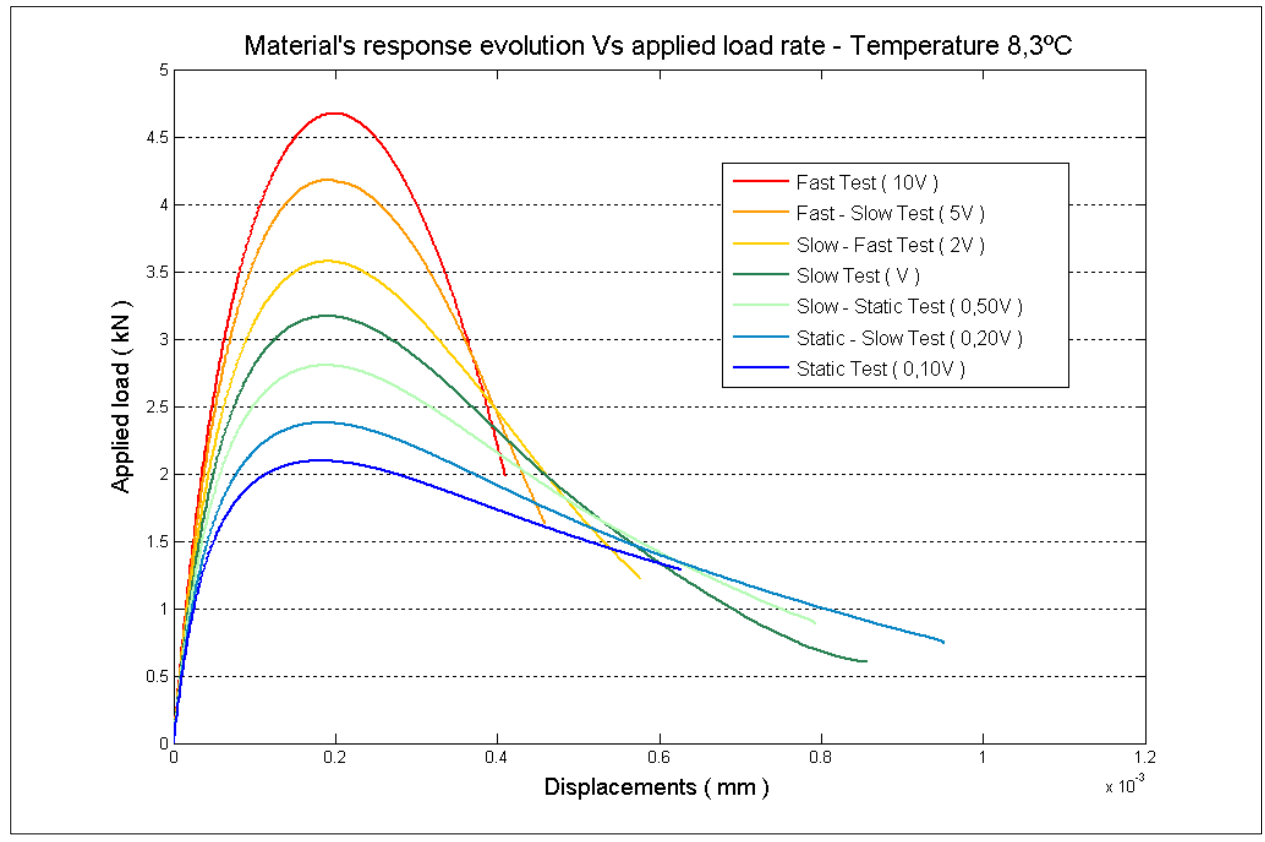

Figure 12.- Evolution of the material's response with Strain rate. Temperature $8,3^{\circ} \mathrm{C}$

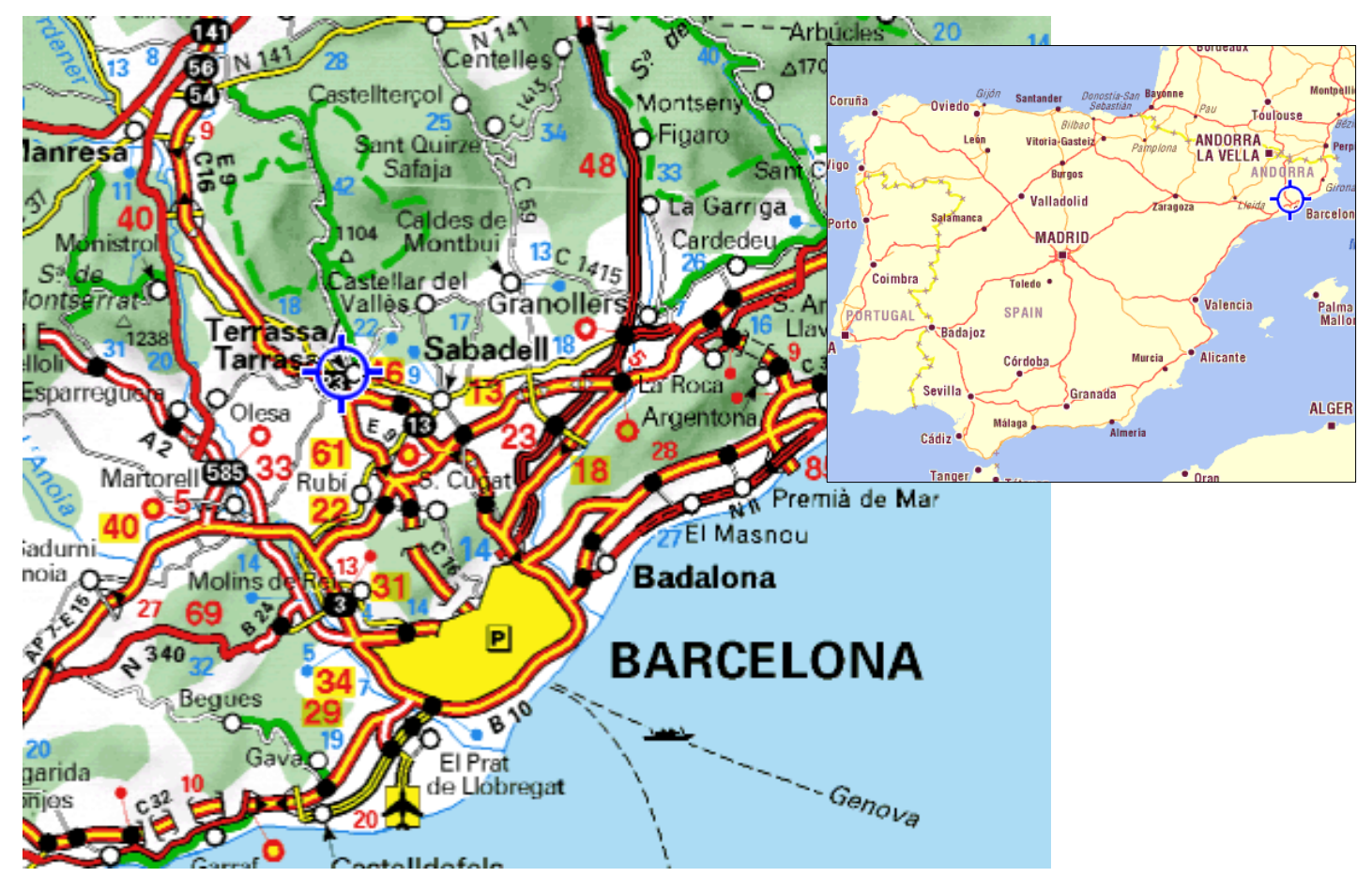

Figure 13.1..- Experimental tracks' location ( PARAMIX ). Barcelona, Spain 


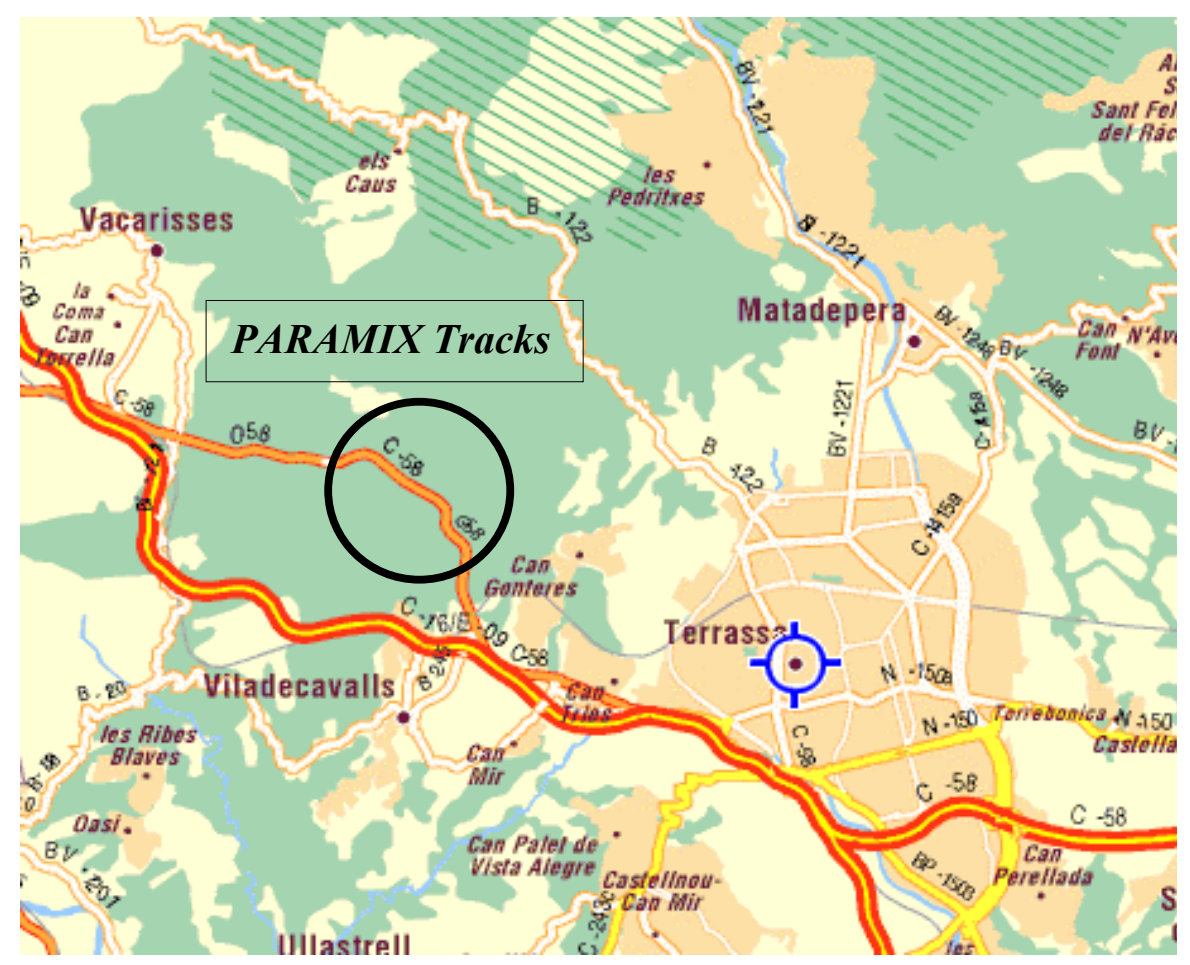

Figure 13.2..- Experimental tracks' location ( PARAMIX )

Track C-58 Terrassa (Barcelona, Spain )

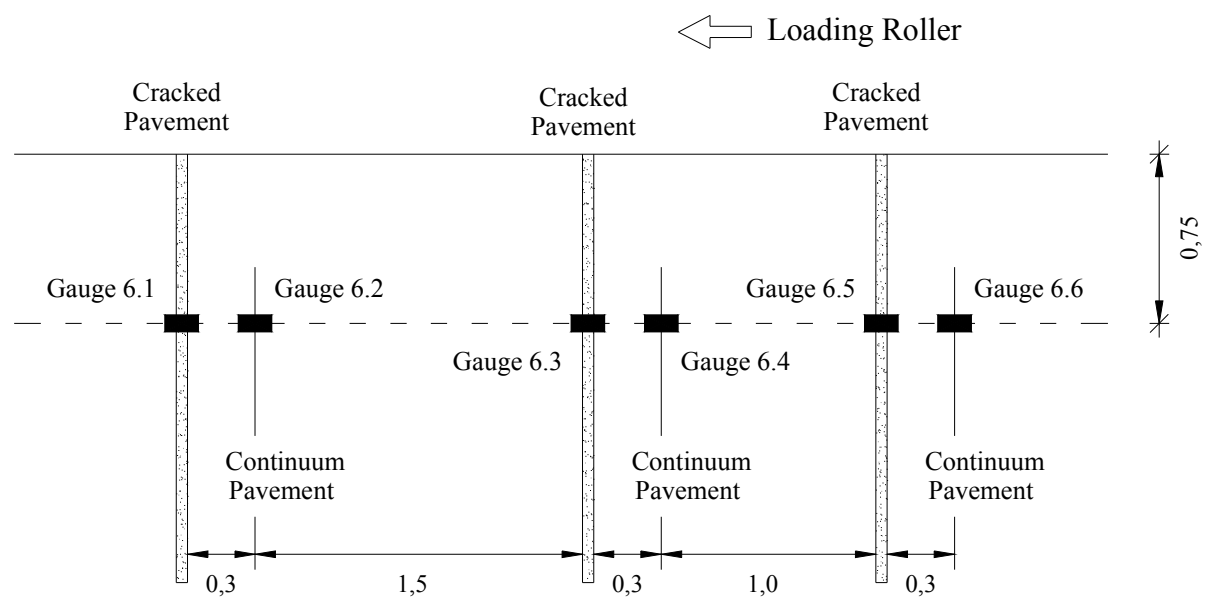

Figure 14.1.- Distance (m) and position of the six strain gauges 


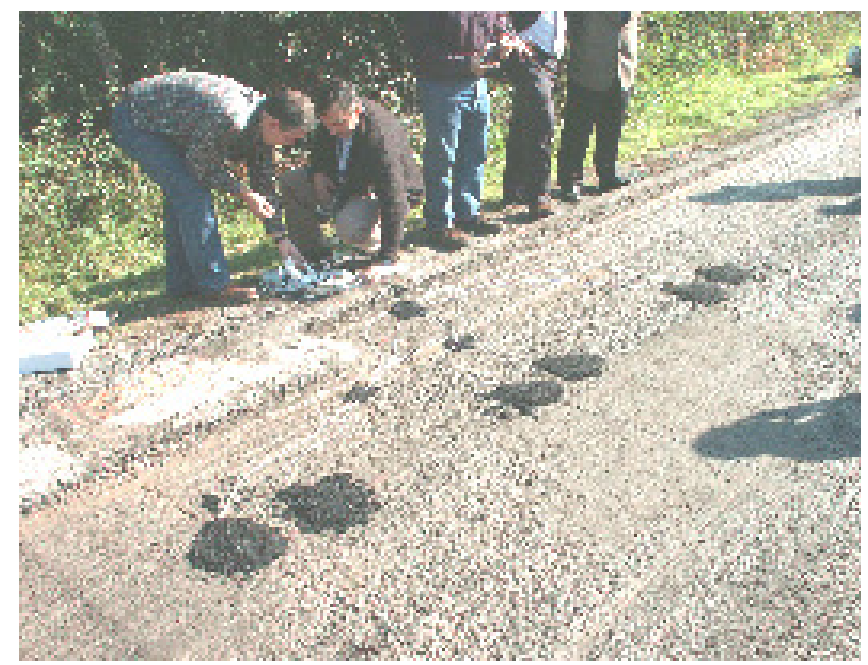

Figure 14.2.- Location of the six strain gauges

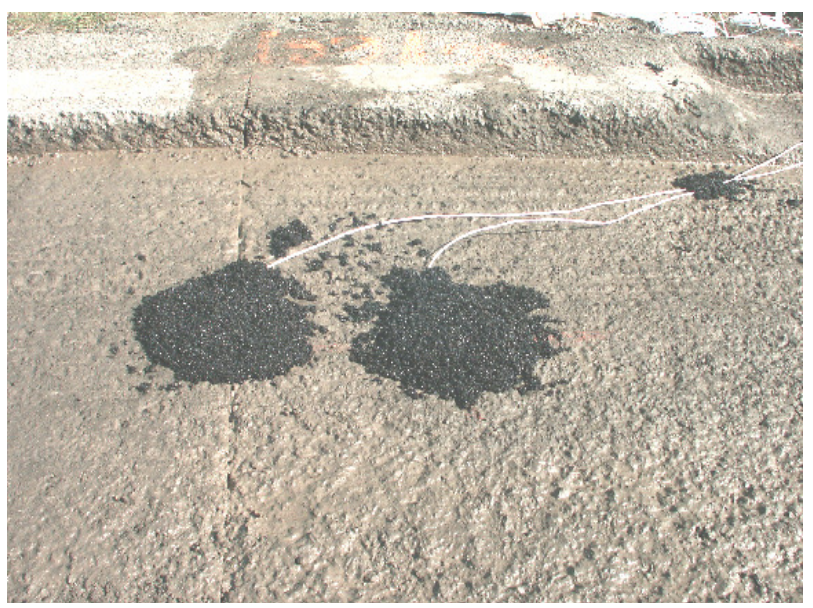

Figure 15.- Cracked and continum asphalt layer

Recycled Asphalt layer

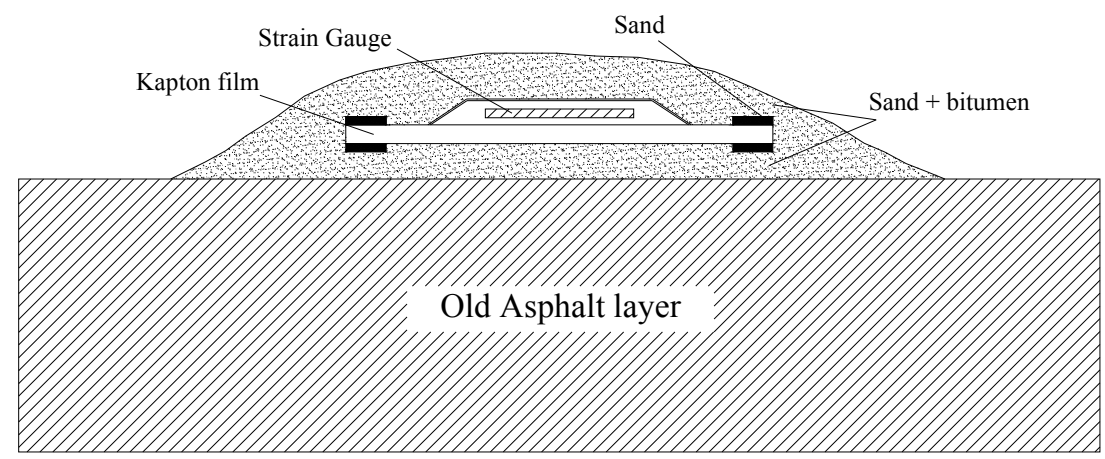

Figure 16.- Embedded gauge ( detail ) 


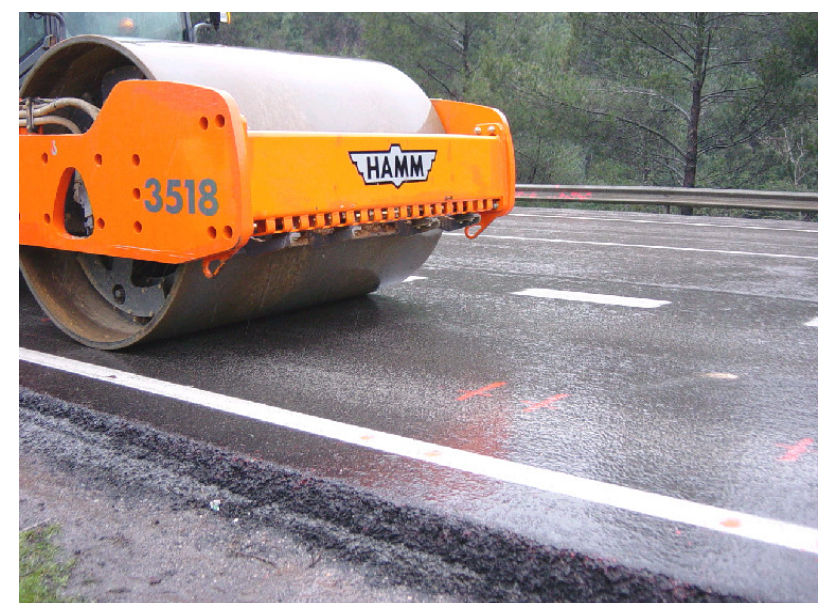

Figure 17.- Pavement structure loading phase

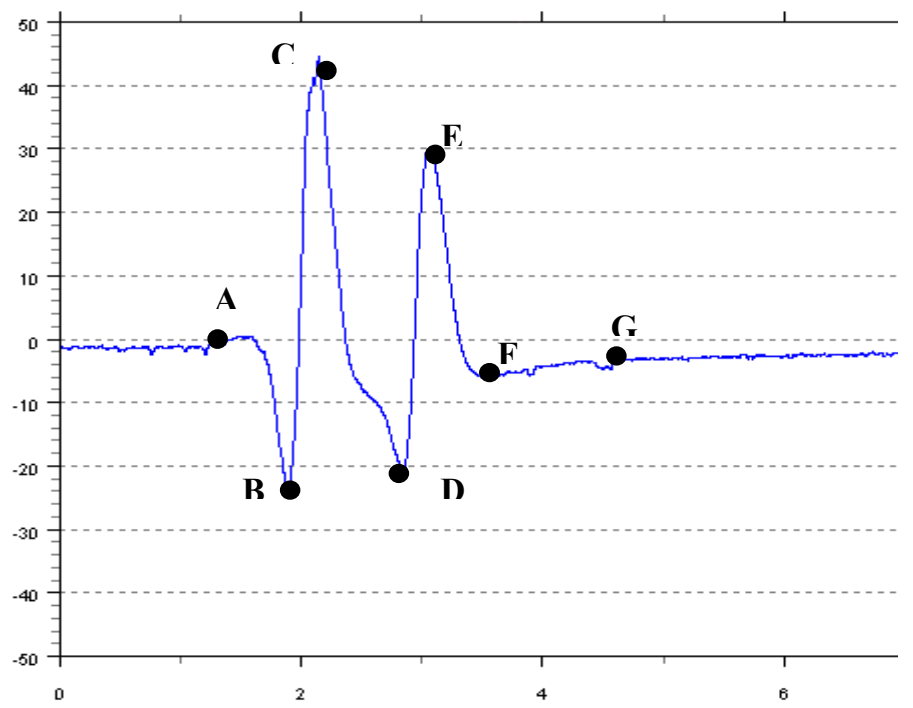

Figure 18.- Horizontal strain - Time evolution.

Experimental curve. Critical points

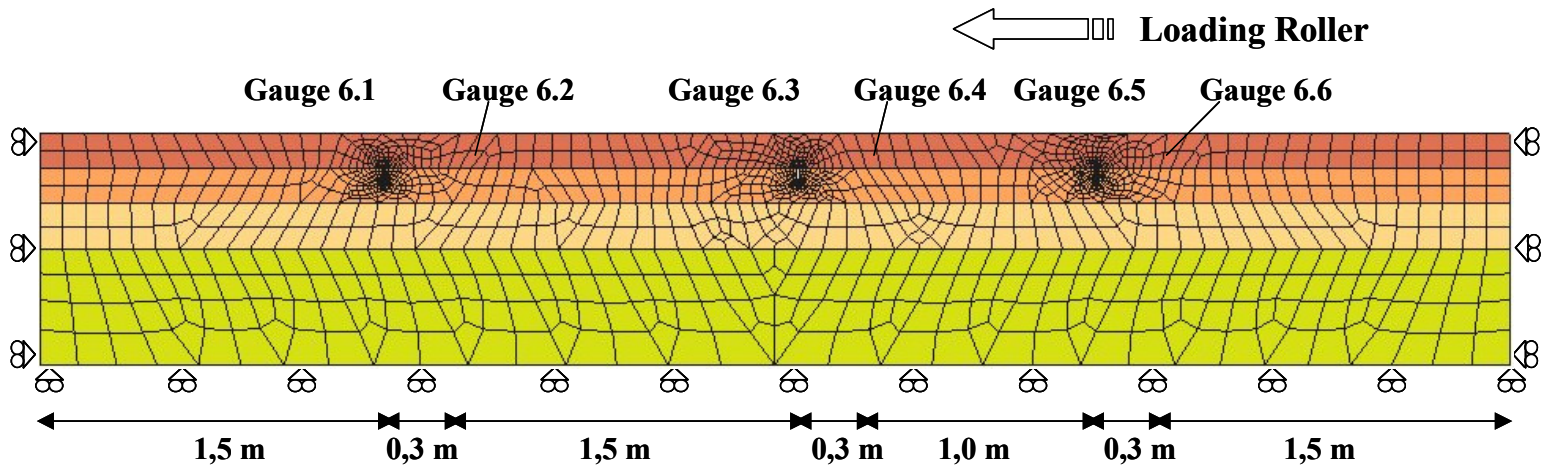

Figure 19.1.- Pavement structure and gauges location Boundary conditions and dimensions 


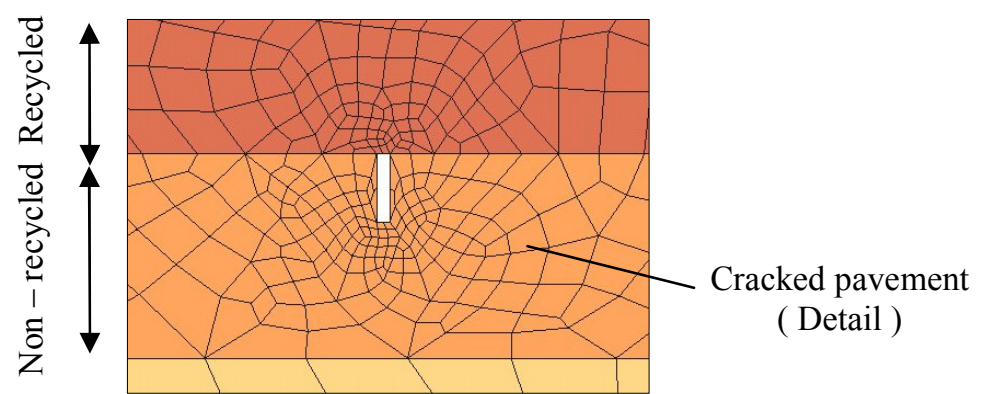

Figure 19.2.- Pavement structure and gauges location

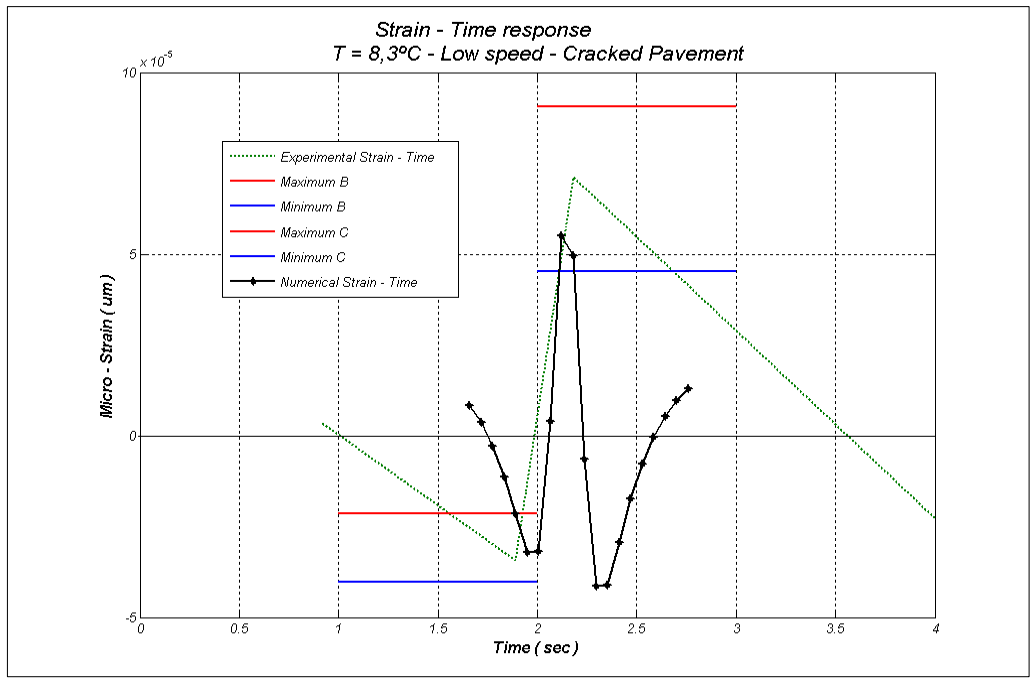

Figure 20.1.-Numerical Vs experimental response. $\mathrm{T}=8,3^{\circ} \mathrm{C}$ Cracked pavement. Low speed of loading

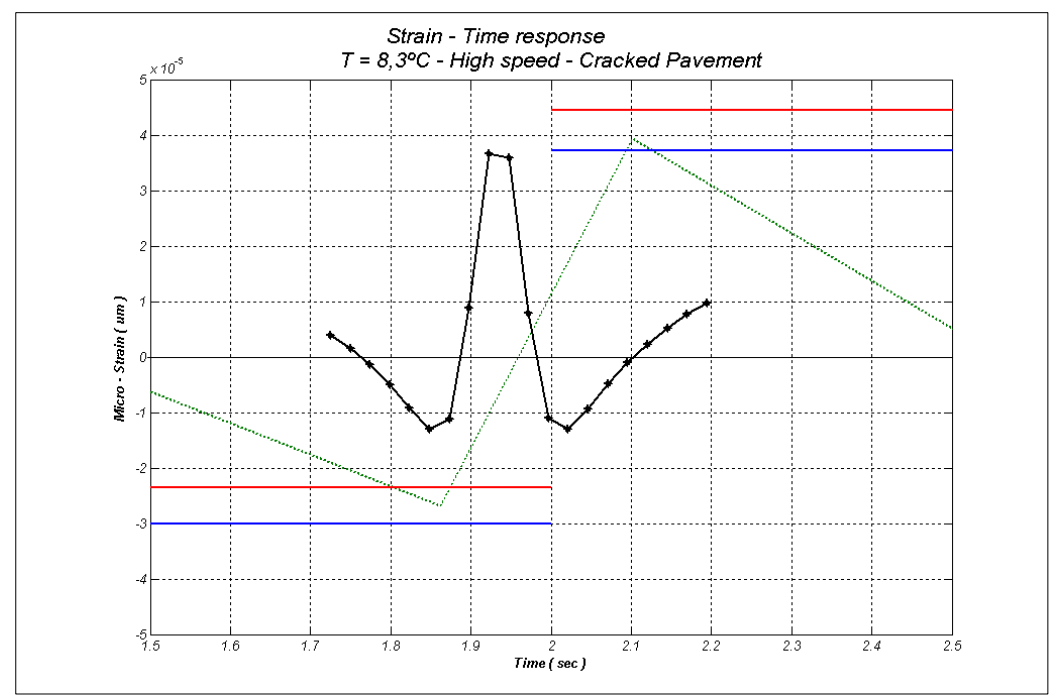

Figure 20.2.- Numerical Vs experimental response. $\mathrm{T}=8,3{ }^{\circ} \mathrm{C}$ Cracked pavement. High speed of loading 


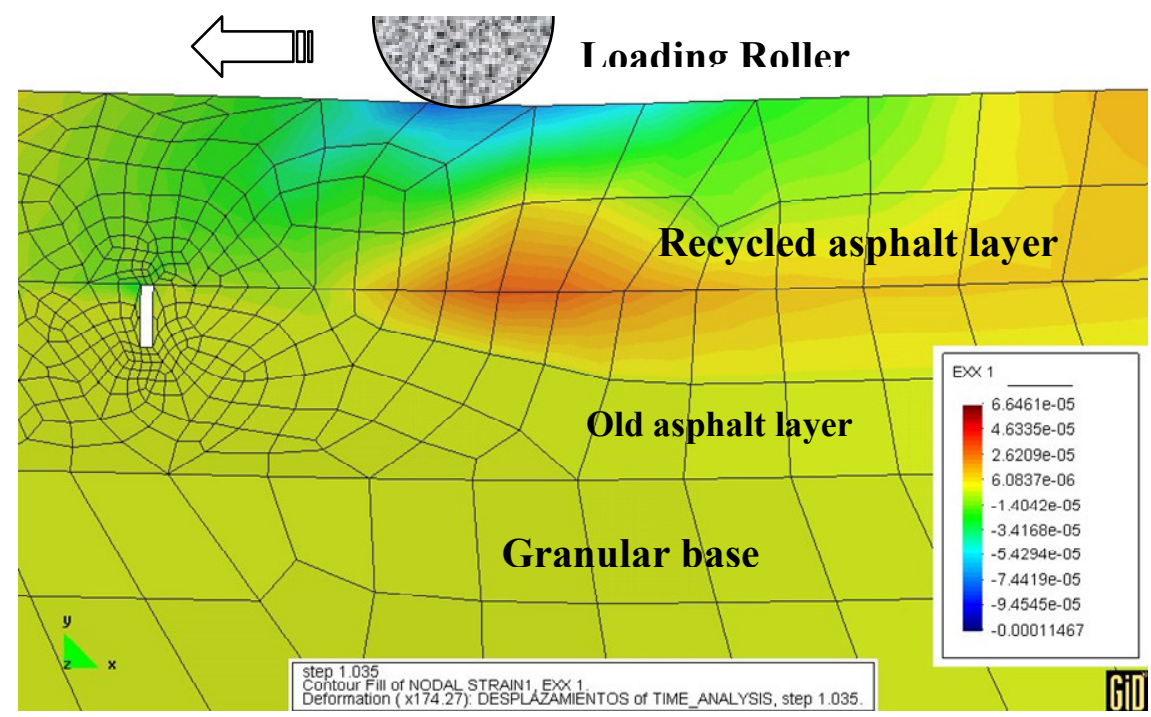

Figure 21.1.- Horizontal strains distribution in Continum pavement Interphase between the asphalt layers

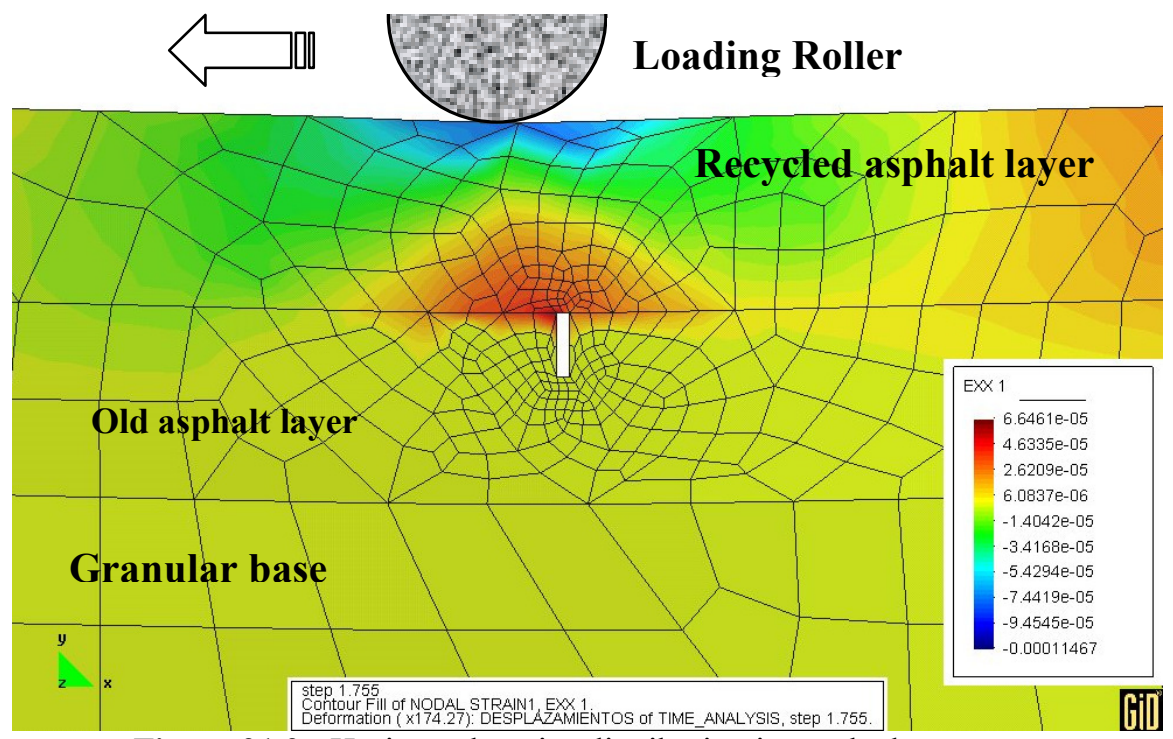

Figure 21.2.- Horizontal strains distribution in cracked pavement Interphase between the asphalt layers 